\title{
What Happens When You Give Money to Panhandlers? The Case of Downtown
}

\author{
Manhattan \\ February 26, 2017 \\ Gwendolyn Dordick-City College, New York, New York \\ Brendan O’Flaherty_Columbia University, New York, New York \\ Jakob Brounstein-Columbia University, New York, New York \\ Srishti Sinha-Columbia University, New York, New York \\ Jungsoo Yoo-- University of Pennsylvania, Philadelphia, Pennsylvania
}

\begin{abstract}
We study panhandling in Downtown Manhattan. Surprisingly few people panhandle there at any given moment: about 8-10 people on average at a busy time, in a small area with an economy the size of Latvia's. The redevelopment of Ground Zero and the resulting surge in economic activity-including the opening of North America's tallest building - changed where panhandlers operated within the neighborhood, but did not significantly increase panhandling overall. The response was muted because the labor supply of panhandlers appears to be inelastic. On the other hand, good places to panhandle are relatively abundant. Hence the benefits of the boom in economic activity accrued mainly to incumbent panhandlers themselves; as would the benefits of greater donor generosity.

Acknowledgments: We are grateful to Rosanne Haggerty for suggesting this project and advising us along the way. We have received helpful comments from Andy Haughwout, Ingrid Gould Ellen, Sun Kyoung Lee, Meiping Sun, Ben Marx, Randy Filer, Julie Wulf, Diana Switaj and from seminar participants at the City College of New York, the City University Graduate Center, Columbia University, the New York Federal Reserve Bank, and New York University. We have received help and data from Maryanne Schretzman, Alison Baumann, Casey Gorrell, Vincent Susi, and the Downtown Alliance. For excellent research assistance we thank Nabeel Ahmed, Shantia Blackwell, Sanat Kapur, Steve Hun Lee, Lester Li, Allen Lipson, Yue Long, Mohamed Hamza Loulichki, Matthew Neal Seyler, Cody Joe Keith Torre, Xinger Wu, and Miryung Yang. Financial support from the Columbia Department of Economics, Program for Economic Research (and the assistance of Juliana Capaldi) is gratefully acknowledged. The errors are our own.
\end{abstract}


In August 2016, Australian Prime Minister Malcolm Turnbull was photographed giving a $\$ 5$ bill $^{1}$ to a panhandler named Peter on a Melbourne sidewalk as the prime minister was about to give a major speech before the Committee for Economic Development of Australia. ${ }^{2}$ As he gave the $\$ 5$ bill with his right hand, a wad of considerably larger bills was visible in his left (Hauser, 2016).

The picture went viral. Almost all comments criticized Turnbull, but disagreed violently on what he had done wrong. Some comments attacked him for giving too little: "Turnbull—a man worth $\$ 133$ million, a man who carries a stash of bank notes in a money clip, a man who donated a cool $\$ 1$ million to his own election campaign — could only spare a fiver to shove in another man's coffee cup," wrote Erin Stewart in Sydney. Other comments attacked him for giving anything at all: Melbourne Lord Mayor Robert Doyle said that giving money to panhandlers entrenches homelessness and that people should donate to organizations that help the homeless instead (Hauser, 2016). Turnbull himself could not explain what he had done: "I know people have got different views on that. But you know, every time I see someone in that situation, I always think: There but for the grace of God go I. It was a human reaction, and I'm sorry if that has disappointed some people. Maybe they think you should not give money to people who are sitting on the street, but I felt sorry for the guy."

\footnotetext{
${ }^{1}$ Equivalent to about USD $\$ 3.75$ at then-current exchange rates.

${ }^{2}$ Peter did not give permission for use of his image (Dobbin 2016), and so we do not reproduce this photograph.
} 
What all the participants in this controversy (except perhaps Peter ${ }^{3}$ ) had in common was ignorance of the consequences of Turnbull's act. Is increased giving to panhandlers likely to trigger more panhandling and more rent-seeking? Is it likely to increase homelessness? Does it somehow get siphoned off in the long run to shadowy figures who control land or some other scarce resource? Or does it mainly benefit people like Peter fairly directly and without large indirect consequences?

One reason why the comments could explode so floridly in so many directions is that no existing literature explores the consequences of panhandling generosity, either theoretically or empirically. This paper aims to fill that void. We develop a rudimentary model of a panhandling market, and estimate several key parameters for downtown Manhattan. We conclude that if inner Melbourne is like downtown Manhattan, Turnbull's generosity had few, if any, perverse or indirect consequences: Peter was better off (he says he used the bill to buy a sausage roll and coffee for lunch (Dobbin 2016)), and nothing much else happened (except some panhandlers may have moved a few blocks).

Our approach and conclusions have many implications beyond judging which Australian politicians are worthy of sainthood. The regulation of panhandling is controversial in almost all parts of the developed world, and the discussions we have witnessed in the US are as poorly informed as the viral reaction to the picture of Turnbull and Peter. Wise policy can be founded only on the kinds of analysis we

\footnotetext{
${ }^{3}$ Peter said: “It's a little stingy, because he's a millionaire, but that's O.K. It's his money, and he worked hard for it."
} 
do in this paper. A companion paper (Dordick et al. 2017) explores policy questions in more detail.

Panhandling also matters because panhandlers are the visible face of extreme poverty in developed countries. Most poor people strive not to be seen or recognized as poor, but successful panhandlers must do the opposite; secret panhandling is an oxymoron. In an afternoon's work, over 10,000 people see the average panhandler in downtown Manhattan-as many people as see the average professor at work over an entire career. Public opinion about panhandling may affect public opinion about poverty to a degree totally disproportionate to the representation of panhandlers among poor people (although Lee and Farrell 2003 find little evidence that exposure to panhandling correlates with attitudes about homelessness). So public opinion about panhandling ought to be well informed.

This paper is based on several summers of research in Manhattan. Some of that research was ethnographic, and some was quantitative-observations of the number of panhandlers by place, time, and date. We draw on both sociological and economic literature.

We define panhandling as asking passers-by for money for use by oneself without offering anything of ostensible value in return. Thus we exclude musicians (however terrible), trinket vendors, mendicant nuns and friars, charity solicitors, massage parlor flyer distributors, costumed characters (who pose for pictures and ask for money), and naked ladies, for instance.

Panhandling is thus a labor market phenomenon-it is defined by what you do to get money when you are awake. It is distinct from homelessness, which is a 
housing market phenomenon—defined by where you sleep. Often colloquial usage confuses the two conditions-for instance, all the media coverage of Turnbull and Peter refers to homelessness, not panhandling. In New York City, a very small fraction of homeless people panhandle, and many panhandlers are not homeless.

Our main finding is that in downtown Manhattan the amount of panhandling is primarily circumscribed by the willingness of people to panhandle, not by the availability of good places to panhandle. Every day, panhandling spots that we think with good reason are excellent stand vacant (see section 7.5.1 below). The supply of panhandling labor also appears to be inelastic: an influx of potential donors caused by an influx of tourists and the redevelopment of Ground Zero and the neighborhood in general did not provoke any corresponding influx of panhandlers.

Since modest changes in environment seem not to change the prevalence of panhandling, ${ }^{4}$ the incidence of policy changes in places like Downtown Manhattan is likely to be pretty simple: a fairly constant group of panhandlers gains or loses; there is no "reserve army of panhandlers" to eliminate any rise in returns by flooding in, and no shadowy "panhandling boss" behind the scenes to soak up any gains by asking more money for right to panhandle in various locations.

4 "Constant prevalence of panhandling" panhandling" does not mean that the same people panhandle every day, any more than "constant prevalence of broken arms" means that the same people break their arms every day. The people who panhandle change frequently, but our empirical finding is that the number of people who do so on any day is relatively impervious to the rewards of panhandling.) 
The changes that occurred in Downtown Manhattan, which we take to be exogenous to panhandling behavior, allow us to identify labor supply elasticity. Our work is context-specific, not universal. For instance, on the crowded sidewalks we studied, aggressive panhandling is a foolhardy strategy, and we saw none of it. (It makes no sense for a panhandler to fixate on a single pedestrian for several minutes and thereby ignore or even alienate dozens or even hundreds of other potential donors.) But aggressive panhandling may be profitable in other environments. The description of Downtown Manhattan helps point to which conclusions might generalize, and which probably do not. (Like Downtown Manhattan, inner Melbourne has dense, quickly moving pedestrian crowds, but the Australian safety net differs greatly from the US, and so some conclusions may not apply to Melbourne).

Section 2 is a literature review. Section 3 provides a brief theory of the panhandling market. Section 4 is a description of downtown Manhattan, and how it was changing in the period we observed. Sections 5 and 6 describe how we gathered the data we use in this paper, and section 7 gives our main empirical results. Section 8 concludes.

Throughout this paper, we have replaced the names of the panhandlers with pseudonyms. Where possible, we have also changed the names of streets. Downtown Manhattan, however, includes places like Ground Zero, Wall Street, and Zuccotti Park that are iconic locations, and we have not tried to disguise them.

\section{Literature Review}


The literature that examines panhandling as a business or tries to understand who benefits from panhandling is sparse. We have found nothing, for instance, that either supports or contradicts Lord Mayor Doyle's claim that giving incentivizes more homelessness and panhandling, or addresses it any other way. In EconLit, most citations to "panhandling," "panhandlers," "beggars," and "begging" use these terms metaphorically—referring, for instance, to beggar-thy-neighbor policies in international trade. The next largest group of papers, primarily outside economics journals, examine either the constitutionality of or political support for vagrancy ordinances and similar measures designed to reduce panhandling (both positively--what cities have them, e.g., Smith 2005--and normatively--e.g., Ellickson 1996), but they do not address how these measures affect panhandlers or potential donors.

Several papers do, however, study panhandling directly. Fogel (1994) contains an illuminating discussion of the relationship between caloric requirements and begging in the Ancien Régime France. Goldstein (1993) and O'Flaherty (1996) report on surveys of panhandlers, but these surveys were small, did not have rigorous sampling designs, did not probe deeply into what panhandlers did, and did not learn anything about donors. They are now also out-of-date.

Outside the US, sociologists and medical researchers have made several valiant estimates of income from panhandling: Adriaenssens and Hendrickx (2011) in Brussels, Bose and Hwang (2002) in Toronto, Butovskaya et al (2004) on trains in Moscow, Jiang and Wu as reported in Lu (1999) in Shanghai, and Murdoch (1994) in London. In most of these studies, mean panhandling income per hour is around the 
minimum wage, maybe a little bit higher. Dordick (1997) includes a great deal of information about panhandling in an ethnographic study of New York street people. Lankenau (1999a, 1999b) examines how panhandlers try to elicit donations. Duneier (1999) provides an illuminating sociocultural account of poor, predominantly black men, who eke out a living as second hand book vendors and as panhandlers on the sidewalks of Greenwich Village. And Snow and Anderson (1993, 2003) situate panhandling as one of the many forms of "shadow work" that street people engage in to make money.

Lee and Farrell (2003) is one of the few papers that use survey data. They use national samples of homeless people to find the extent of panhandling activity in this population (a distinct minority), and a national sample of domiciled people to find the extent of experience with panhandling, the correlates of giving, and the correlates of attitudes toward homelessness. The proportion of homeless people who panhandled was small, but a majority of domiciled people said they gave to panhandlers at least occasionally. Almost a quarter said they gave regularly. Few people changed activities in order to avoid panhandling.

\section{Models of Panhandling, Downtown Style}

Before we can present empirical results, we need a model for understanding the data. We proceed with a series of increasingly complicated and increasingly realistic models.

We think of Downtown Manhattan as a collection of locations (block-fronts), each of which usually fits no more than one panhandler. Each location $l$ has a rate of 
return $g_{l}$ at which a panhandler in that location would receive donations per unit time. We abstract for now from effort decisions by panhandlers, and from any differences in their ability to get donations at a particular location-for instance, because they are well known there. The rate of donations, however, may vary with time and weather.

Occasionally a pair of panhandlers will work together, and occasionally two panhandlers, operating independently, will occupy different parts of the same block front. We will consider two different methods for treating these rare occurrences, and show later that our major results are robust to the choice of method.

We will begin from the simplest case and add complexity.

\subsection{Locations as Islands}

In the simplest case, we think of each location as a separate island. On each island, panhandling activity is a semi-Markov process.

The rate at which entry occurs is a weakly increasing isoelastic function of the rate of return:

$$
\mu g_{l}^{m}, \quad m \geq 0 .
$$

When the location is occupied, the rate at which exit occurs is also a function of the rate of return:

$$
\lambda g_{l}^{-x} .
$$

Let $\pi(l)$ denote the steady-state expected population of location $l$. In the steady state

$$
\lambda g_{l}^{-x} \pi(l)=\mu g_{l}^{m},
$$

and so 


$$
\pi(l)=\eta g_{l}^{\varepsilon},
$$

where $\eta=\mu / \lambda$ and $\varepsilon=m+x$. Taking logs:

$$
\ln \pi(l)=\ln \eta+\varepsilon \ln g_{l} .
$$

Since $\pi(l)$ is the expected number of panhandlers at location $l$ in the steady state, a Poisson regression would recover $\varepsilon$ if we knew $g_{l}$ (or some multiple) at every location.

We call $\varepsilon$ the "supply elasticity" in an obvious analogy to standard labor economics: $m$ is like the elasticity at the extensive margin and $x$ is like the elasticity at the intensive margin. The elasticity at the extensive margin depends on the heterogeneity of reservation wages among potential panhandlers, and the elasticity at the intensive margin depends on the rate at which panhandlers get tired and the rate at which better opportunities appear (in other words, how the instantaneous reservation wage changes). Note that we have not required that $x>0$ : the individual supply curves may be backward bending. Some of the panhandlers we have talked with have described themselves as target earners, and so it might be the case that $x<0$.

Heterogeneity in locations, on the other hand, is represented by the variance in $g_{l}$. In the steady state, the more lucrative locations are more likely to be occupied, and the panhandlers with lower reservation wages are more likely to be working, but there are no hard-and-fast cutoffs as there are in a standard market. Pairings between locations and panhandlers that would not occur in a market and that would not be sanctioned by an omniscient Paretian planner sometimes occur, and pairings 
that a market or an omniscient planner would produce sometimes do not occur. In this model a demand shock appears as an increase (or decrease) in the rate of return in some or all locations. A positive demand shock increases panhandling at the affected locations as long as $\varepsilon>0$.

An alternative formulation is to assume that no more than one panhandler can occupy a location at the same time (or to define locations as so small that only one person can occupy them, or to consider a pair of panhandlers working together as a single entity). Then in the steady state the average rate at which panhandlers enter is

$$
\mu g_{l}^{m}[1-\pi(l)] .
$$

The rate of exit is the same as in the previous case. Then in the steady state

$$
\lambda g_{l}^{-x} \pi(l)=\mu g_{l}^{m}[1-\pi(l)],
$$

and so

$$
\frac{\pi(l)}{1-\pi(l)}=\eta g_{l}^{\varepsilon}
$$

Taking logs:

$$
\ln \frac{\pi(l)}{1-\pi(l)}=\ln \eta+\varepsilon \ln g_{l} .
$$

Then a logit regression rather than a Poisson regression can recover the supply elasticity. Accordingly, we will use both Poisson and logit regressions.

Our model, then, is one of panhandlers who are poorly informed (although not completely uninformed), and poorly organized. They do not immediately go to the best available location, they do not trade or bargain among themselves actively 
or even communicate much, and they do not follow orders designed to maximize gross revenue. These assumptions about panhandlers are based on several conclusions we have reached through ethnographic research.

First, panhandlers, even experienced ones (those who have been working at the same location for an extended period of time, perhaps years), do not know a lot about alternative locations. None could articulate why they were working in their current location rather than somewhere else, although some had had experience in other spots. For instance, Freddy had panhandled in several locations before he started in the place where we saw him most, and he told us, "This spot just seems to work." ${ }^{\prime}$. Donations are a random variable with a large variance, and so learning about their central tendencies is likely to be very slow. We were unable to speak with the panhandlers who were not experienced, though presumably their information is even less adequate.

Second, we witnessed nothing like a monopolist or a competitive market. If someone controlled the rights to panhandle downtown and extorted tribute from panhandlers for their use of this space, no one told us about it. We also saw no bargaining over locations of any kind. We observed few ties between panhandlers.

Panhandling locations seem to be allocated among panhandlers the way seats on a half-empty bus are allocated: first come first served, no monetary

\footnotetext{
${ }^{5}$ While Freddie did not articulate what was good about his location, he had developed a relationship with a nearby pizza store that allowed him to access their restroom, which was important to him because he needed a handicapped-accessible facility.
} 
transactions, and better seats more likely to be occupied. That is how the model is developed.

What about the question of whether a location can accommodate more than one panhandler? That is, should we use the Poisson or the logit specification?

There does seem to be a norm against one panhandler displacing another. For instance, we met Theo at a corner that did not seem to have a lot of foot traffic and he told us that he was getting donations, but at a slow clip. He said he usually worked on the other side of the street, but when he arrived today at noon, later than usual, another panhandler was already there. Citing first-come-first-serve, he moved to his present location. He was clearly more skilled and aggressive than the panhandler who had arrived first—-that panhandler was asleep and his cup was empty. But Theo was not trying to displace him.

Part of the reason for this norm may be practical: an arriving panhandler does not have a good way of dislodging an incumbent. A fight between panhandlers is likely to draw unwelcome attention—from police, merchants, or potential donors, for instance-and so any victory is likely to be Pyrrhic. Fights occur, but they are rare.

What about paying an incumbent to leave peacefully? We have not seen this occur, and the idea was foreign to almost all of the panhandlers we talked to. ${ }^{6}$ At the start of a session, a panhandler may not have enough cash to pay someone to leave, may not be willing to show that cash if he had it, and may not wish to set a precedent that would encourage somebody to set up shop in the disputed place

\footnotetext{
${ }^{6}$ When asked what he would do if someone was in his spot, one panhandler, Leroy, said that he would pay them $\$ 2.00$ to leave. However, this is what he said he would do. We have no evidence that he in fact did this. Also, he was not referring to a panhandler, but to someone sleeping in his spot.
} 
regularly and collect from him rather than regular donors. We have never seen one passenger pay another to give up a seat on a bus or train either.

But this norm does not always prevent one panhandler from working close to another (we have witnessed a fight over this issue-the only fight we saw). Of course, being very close to another panhandler may reduce the rate of return that a panhandler realizes (see section 4.3): donors may be loath to donate to panhandlers or may have only a small amount of expendable currency.

Thus probably the most general way to resolve the question of twopanhandlers-on-the-same-block-front is to propose that each receives only a fraction $f$ of what he would receive if he were alone. We don't know what $f$ is, but the Poisson and logit specifications are polar cases of the values that $f$ could take. If $f=0$, then the rate of return to a second entering panhandler is zero. So panhandlers will never arrive at occupied locations and the logit specification holds precisely. If $f=1$, an already-occupied location is just like an unoccupied location as far as new arrivals are concerned, and the Poisson specification holds precisely. The two specifications bound the possibilities.

\subsection{Moving between Locations}

Panhandlers sometimes move between locations, contrary to the isolation assumptions of section 3.1. (Passengers move between seats on a half-empty bus, 
too.) Such movement may cause greater concentration of panhandlers in the better locations.

Consider the Poisson version of the model. Conditional on location $i$ being occupied, let $\theta_{i j}$ be the rate at which movement from location $i$ to location $j$ occurs. We assume that $\theta_{i j}$ is decreasing in the rate of return at the origin and increasing in the rate of return at the destination: panhandlers are more likely to leave worse spots and go to better ones. Specifically

$$
\theta_{i j}=\tau g_{i}^{-y} g_{j}^{n} .
$$

This is essentially a simple gravity equation. Complete isolation is a special case with $\tau=0$.

In the steady state, the average rate of outflow from location $i$ is

$$
\pi(i)=\left\{\lambda g_{i}^{-x}+\sum_{j \neq i} \tau g_{i}^{-y} g_{j}^{n}\right\} .
$$

The rate of inflow to location $i$ is

$$
\mu g_{i}^{m}+\sum_{j \neq i} \tau \pi(j) g_{j}^{-y} g_{i}^{n} .
$$

Hence in the steady state

$$
\pi(i)=\frac{\mu g_{i}^{m}+\sum_{j \neq i} \tau \pi(j) g_{j}^{-y} g_{i}^{n}}{\lambda g_{i}^{-x}+\sum_{j \neq i} \tau g_{i}^{-y} g_{j}^{n}}
$$

With some difficulty, this system of equations can be solved.

Specifically, let

$$
\alpha_{i}=\frac{\lambda g_{i}^{-x}}{\lambda g_{i}^{-x}+\sum_{j \neq i} \tau g_{i}^{-y} g_{j}^{n}}
$$


be the weight on the no-internal-movement steady state. Note that if $\tau=0, \alpha_{i}=1$ and if $\tau$ goes to infinity, $\alpha_{i}$ goes to zero. If $x<y$ (the elasticity of external leaving is less than the elasticity of internal leaving), than $\alpha_{i}$ is greater for larger values of $g_{i}$.

Also, let

$$
\beta_{j i}=\frac{g_{j}^{n}}{\sum_{k \neq i} g_{k}^{n}} .
$$

Then:

$$
\pi(i)=\alpha_{i} \eta g_{i}^{\varepsilon}+\left(1-\alpha_{i}\right) \eta g_{i}^{\delta} \sum_{j \neq i} \beta_{j i} g_{j}^{\delta-\varepsilon}
$$

(A similar formula applies for the logit case.)

The intuition is that if $\tau$ is very small, the steady state probability $\pi(i)$ will be almost proportional to $g_{i}^{\varepsilon}$, as before, where $\varepsilon=m+x$ is the "external" elasticity of supply. When there is little movement between locations, such movement doesn't matter much. If $\tau$ is very large, on the other hand, then approximately only internal movements matter in the steady state, and $\pi(i)$ will be almost proportional to $g_{i}^{\delta}$, as before, where $\delta=n+y$ is the "internal" elasticity of supply. For intermediate values of $\tau, \pi(i)$ is a weighted average of these two values. Thus if $\delta>\varepsilon$ (the internal elasticity of supply is greater than the external), then increasing $\tau$, the rate of internal movement, makes the concentration of panhandlers in the more lucrative locations greater. If $\delta<\varepsilon$, the opposite occurs. We have no strong feelings about whether the internal elasticity is greater than the external, but an intuition suggests that it is: moving from one block to another is easier than taking up or leaving panhandling. Thus we will write the sequel under the assumption that $\delta>\varepsilon$, and 
our empirical work in section 6 suggests that it is (but we cannot reject the hypothesis that it is not).

Notice that if $\delta>\varepsilon$, the elasticity of panhandling with respect to the rate of return will be greater in the time series than in the cross-section. This differs from the isolation case in section 4.1 where the time series and cross-section elasticities were the same. Movement between locations also means that location populations will no longer be independent

\subsection{External Effects}

The final extension is to allow the presence of panhandling at one location to affect the rate of return to panhandling at other locations. For instance, if donors have only a limited amount of spare change and most pedestrians walk from east to west on a particular street at a particular time, the presence of a panhandler at an eastern location may reduce the rate of return at a western location. Alternatively, simple presence of a large number of panhandlers may suggest to some potential donors that "everybody is panhandling," not just the neediest, and lead them to conclude that the average panhandler is less deserving. (A fully worked out version of this model can be found in Dordick and O'Flaherty 2014). Thus, for instance, some panhandlers in 2013 told us that Occupy Wall Street (OWS) had hurt their business because Wall Streeters did not think that OWS panhandlers were welldeserving, and confused regular panhandlers with the OWS variant. One panhandler said, "OWS people take money away from me." He told us that they panhandle to get money from the folks that they hate, and referred to them as "a 
bunch of trust fund babies." So external effects can be either positional or informational.

To begin, assume no moves between locations-the model of section 3.1. Consider two locations, 1 and 2. Assume that when a panhandler is working at location 1 the rate of return at location 2 falls. Then location 2 will be less likely to be occupied when location 1 is occupied, holding all other conditions constant. This is testable, if we assume no movement between locations.

When moves between locations are possible, this conclusion needs to be modified because such moves may not be distinguishable from externalities. Suppose $g_{1}>g_{2}$. Then even without a negative externality location 2 will be less likely to be occupied when location 1 occupied, because a panhandler at location 2 is likely to move to location 1 , and leave location 2 empty. An externality from location 1 to location 2 is qualitatively observationally equivalent to a movement from 2 to 1 , assuming that 1 is the more lucrative location. On the other hand, if $g_{1}<g_{2}$, a finding that location 2 is less likely to be occupied when location 1 is occupied is strong evidence for an externality in the hypothesized direction.

\subsection{Information and Panhandling Skill}

In the preceding sections we assumed that all panhandlers looked the same to all potential donors; active panhandlers differed only in the location they were using. But panhandlers also differ in other relevant ways, especially in the impression that they make on potential donors. 
The impression is important because many potential donors, even those who are philanthropically inclined, believe that most panhandlers are fraudulent in one way or another. Almost all casual conversations we have had with affluent New Yorkers about panhandling have begun with either a declaration that most panhandlers are scams, or a question about whether we think they are scams. To make more money than average, a panhandler has to persuade some potential donors that he is more deserving than the average panhandler.

We have not observed many clever strategies for doing so. One panhandler we saw in 2014 used humorous signs. But he was not around in 2015, and we do not know how successful he was. No one imitated him. Several panhandlers are wheelchair-bound, but anyone can rent a wheelchair and sit in it. These panhandlers appear to be more successful than average, but their success is probably not solely due to their wheelchairs.

Persistence is the main way that a panhandler can set himself or herself apart from peers. Persistent panhandlers can develop a regular "customer base"-a group of donors who recognize them and give regularly. Persistence is a signal that a panhandler has a low reservation wage-otherwise he would not be on the street that often—and good work habits—someone who abused drugs or alcohol would probably not be able to maintain regular hours. Seeing someone over and over again also makes him appear to be more of a friend, or at least a human, and less of a symbol. Not all panhandlers are persistent, and not all have regular customers, but a few do, and they stand out and probably account for a significant fraction of the money that panhandlers collect. 
Two external conditions must be met for a panhandler to develop a regular customer base. First, he needs a flow of the same people on the same block for months or years. Thus a regular customer base consists of workers or residents, not tourists.

Second, the location where he meets his base must be secure, both from other panhandlers and from construction crews. If the location disappears or is taken over by another panhandler, the customer base is lost too-he can't email or text them with the new location. For panhandlers, avoiding construction crews downtown is probably purely a matter of luck. Avoiding interloping panhandlers is probably simpler: if there is no shortage of fine locations, no interloper has a large incentive to displace an incumbent. Established panhandlers may also have made friends with security people and maintenance people from abutting properties, and so have allies in deterring interlopers. ${ }^{7}$

\section{Downtown Manhattan}

\subsection{The Basic Setting}

Our research has concentrated on Manhattan south of Duane Street, which we call “Downtown Manhattan." Within this area of under a square mile ${ }^{8}$, we concentrate on the corridor within two or three blocks of Broadway, because there

\footnotetext{
${ }^{7}$ Eli successfully used his relationships with the police to have panhandlers either removed from his spot or from nearby on his block front. In fact, he did have the police remove a woman panhandling close to the subway entrance near Church Street with her young son and another wheelchair bound panhandler who situated himself closer to the PATH station.

${ }^{8}$ New York City Community District 1 has an area of 1.49 square miles, according to the Department of City Planning 2016. The community district includes the area we study, plus Tribeca, Governor's Island, Liberty Island, and Ellis Island. The islands alone have an area of about 0.3 square miles.
} 
are few panhandlers outside this corridor. Our data for non-panhandling activity, however, cover New York City Community District 1, a slightly larger area.

Downtown Manhattan is rich, bustling, and crowded. In the third quarter of 2014 , about 266,000 people worked in this area, with an average private sector salary of $\$ 148,000$ (Downtown Alliance 2015). Wall Street and New York Federal Reserve Bank are located in Downtown Manhattan, but many people work in nonfinancial jobs too. New York City Hall and many municipal offices are found here, as well as a large number of state employees. There is also a growing representation of media companies, most notably Conde Nast and Time (Downtown Alliance 2016). Many people also work in low-paying service and retail jobs in Downtown Manhattan.

In addition, 9.6 million tourists visited in the third quarter of 2014, and 61,000 residents lived in the area (with an average household income of $\$ 204,000$ ) (Downtown Alliance 2015). Few people travel by car, where they would be hard for panhandlers to reach. (Parking spots in nearby neighborhoods cost up to $\$ 1$ million (Green, 2015). On an average day, about 430,000 people entered Downtown Manhattan by public transit, excluding buses. The sidewalks are jammed: a 2006 Department of City Planning report (NYC Department of City Planning 2006) found many block fronts where over 2,000 people passed in an hour-and this was early in Downtown's recovery from 9/11. The GDP of Downtown Manhattan is probably greater than that of Latvia or Wyoming. Downtown seems like a good place to panhandle.

\subsection{How it Changed}


Between summer 2014 and summer 2015, prospects for panhandling seem to have improved notably. The tallest building in the Western Hemisphere, One World Trade Center, opened in November 2014, and its popular observation deck opened in May 2015. The September 11 Museum had opened right before the summer started in 2014, but had substantially more visitors in 2015 than $2014 .{ }^{9}$ The new Fulton Transportation Center opened partially in winter 2014, making access to Downtown Manhattan easier for many people in New York City (but also offering pedestrians more opportunities to travel underground).

Table 1 pulls together information about changes in various kinds of measured activity in Downtown Manhattan between 2014 and 2015. The outstanding feature in this table is the surge in tourism, and tourism-related activity - a growth of almost 30 percent in the number of tourists visiting the neighborhood. Employment and resident population grew too, but relatively slowly. The spending power metric combines both tourists and more permanent people, and rose almost 12 percent.

When we look at disaggregated data for different parts of Downtown, the surge in tourism is apparent. We have two sources of information on pedestrian activity: New York City Department of Transportation (DoT) pedestrian counts, and Metropolitan Transit Authority (MTA) swipe data. Neither is perfect or complete.

The DoT counts cover only a few block fronts. Since 2007, the DoT has been counting pedestrians twice a year, in May and in September, at 114 locations in New

\footnotetext{
${ }_{9}$ The 2014 annual report said that there had been 1.8 million visitors (September 11 Museum 2014) and the 2015 annual report said that there had been over 4 million cumulative visitors (September 11 Museum 2015).
} 
York City. Seven of these are in Downtown Manhattan. The DoT counts pedestrians on both sides of the street. In each month, the counts take place on a weekday (not Monday or Friday) between 7 am and 9 am and between $4 \mathrm{pm}$ and $7 \mathrm{pm}$, and on a Saturday between noon and $2 \mathrm{pm}$. We concentrate on the weekday afternoon counts.

Table 2 shows these counts for the seven downtown "streetlines."10 For most of the streetlines no clear comparison between 2014 and 2015 is obvious because the changes are small or are not consistent in direction between months. The exception is Trinity Place between Rector and Thames, which witnessed a large increase in pedestrian traffic. This is close to Ground Zero, a major tourist area.

The other disaggregated source is Metrocard swipe data for each of the 14 subway stations in Downtown Manhattan. We have weekly swipe data by type of Metrocards from 2014 and 2015. We pay special attention to swipes of 30-day unlimited Metrocards. These cards are cheaper than pay-per-ride cards for more than 43 trips a month. So it is mainly workers who use these cards.

Table 3 presents data on the total number of swipes and the number of 30day swipes for the weeks between Fourth of July and Labor Day for each of 10 stations. It is impossible to match stations with tourist activity tightly because many stations serve both tourists and non-tourists, and because several stations cover many blocks underground. Nevertheless, we divide the stations into those that are close to major tourist destinations (Ground Zero, the Bull, and the New York Stock Exchange), and those that are not. In the aggregate, swipes increase more in the

10 "Streetlines" are lines that cover sidewalks on both sides of a street. 
stations closer to the tourist attractions, and swipes by full fare cards increase more than swipes by 30-day cards. (Some of the large changes, of course, may be due to construction activity, not to changes in activity above ground. However, subway construction that changed the number of swipes would affect pedestrian patterns above ground, which is what we ultimately care about.)

\section{Methods for Ethnographic Research}

In the summer of 2012 we began to systematically observe panhandlers in Downtown Manhattan. Our initial observations were unobtrusive. In the early stages when we encountered panhandlers we logged our observations into field notes and Google Maps. These notes allowed us to write detailed descriptions of panhandlers, the locations, and some rough estimates of donor activity. The Maps gave us snapshots of the overall landscape. We did not take photographs of panhandlers or locations as we felt such data may jeopardize confidentiality should they fall into the wrong hands.

These initial observations provided us with a pool of potential panhandlers whom we could speak with over a period of time. During the summers of 2012, 2013, 2014 and 2015 we engaged in repeated conversational interviews with a number of panhandlers. These conversations were often brief (we encountered panhandlers as they were working and didn't want to reduce their income). Engaging panhandlers while they were working gave us the opportunity to observe not only their strategies, but more importantly, observe how often and how much donors would drop into their cups. As with the initial observations, the data were systematically logged into detailed field notes. 


\section{Methods for Quantitative Research}

During the summers of 2013,2014, and 2015, we, and many research assistants conducted a large number of "walks" in Downtown Manhattan. In 2013, we laid out four routes, each of which a person could walk in 20-40 minutes. We began with a "pedestrian level of service study" that the New York City Department of City Planning (DCP) had published for downtown in 2006 (New York Department of City Planning, 2006). As part of that study, they measured pedestrian flows at 62 locations at three times of the day (morning rush hour, midday, and evening rush hour). The unit of observation is a "block-front": a sidewalk from one corner to the next on one side of the street. Major physical changes had not yet occurred downtown when this study was done. The 62 block-fronts were not randomly selected, but the DCP had some preference for subway entrances. They included only 12 block-fronts on Broadway, although there are 28 block-fronts on Broadway below Chambers Street, and all of them are crowded.

We divided the 62 DCP block-fronts into three classes based on midday flows: heavy traffic—over 2,000 pedestrians an hour; moderate traffic—between 1,100 and 1,999 pedestrians an hour; and light traffic-under 1,100 pedestrians an hour. There were 19 heavy traffic block-fronts, 30 moderate, and 13 light. We used the 49 heavy and moderate traffic block-fronts for our walks. To these we added the remaining 16 block fronts on Broadway below Chambers; these are concentrated between Fulton and Wall Streets. In the DCP data set, all 12 Broadway block-fronts had pedestrian flows over 2,000 an hour, and casual observation suggests no substantial diminution of pedestrian traffic outside the DCP data set. We call these 
the added block-fronts. Broadway sidewalks are usually wide, and shade is reasonably abundant. Finally, we added 6 block-fronts outside these sets where we had seen panhandlers sometime during the summer of 2013; we call these the established block-fronts.

In all, we had 71 block fronts. We divided these into four routes based on a rough idea of what would be easy to walk. We called these routes Eastern Broadway, Western Broadway, Northwest, and Crossover (because it was the only route that crossed Broadway). They were designed in 2013 to encompass virtually all panhandling activity downtown. In 2015, two extremely savvy research assistants searched the rest of downtown looking for panhandling activity that was not on the routes, and did not find any.

Figure 1 is a map of the four routes.

Because of the major change in tourism between 2014 and 2015, we divided the block-fronts in our walks into three sets, which we called "zones." The "tourist zone" consisted of the block fronts with the greatest tourist activity: the block-fronts adjacent to Ground Zero (including block-fronts perpendicular to the Ground Zero boundary), the block-fronts immediately adjacent to the bull at the foot of Broadway, and block-fronts adjacent to Federal Hall and the New York Stock Exchange. The second zone we called "Broadway": all the block fronts on Broadway except those adjacent to the bull. This zone is dominated by employment. The third zone is everything else. Figure 2 is a map of these zones.

7. Empirical Results

7.1 How Many Panhandlers Are There at a Point in Time? 
Our first results are about the number of panhandlers. We can record the prevalence of panhandling, not the incidence, because we did not attempt to identify individual panhandlers and trace their activities over time. On average, about 8-10 panhandlers were working in Downtown Manhattan. This is an average over the times we surveyed. Table 4 shows this estimate in detail.

The outstanding implication of this table is that very few people panhandle at one time. Recall that Downtown Manhattan has the GDP of Latvia or Wyoming, concentrated in about a square mile; it is full of tourists and rich people who are walking. Panhandling is not a widespread occupation, and only slightly more than a tenth of these highly-selected block fronts have panhandlers on them. In particular, this result suggests that the point-in-time count for New York City panhandlers is almost surely less than a thousand. By contrast, in summer 2015, approximately 60,000 people were in city homeless shelters (New York City Department of Homeless Services 2016a) and the January 2015 street count had been 3200 (New York City Department of Homeless Services, 2016b).

Notice that this estimate of 8-10 panhandlers is for the average time we observed. The walks tended to be concentrated in the heavier times for panhandling. Figure 3 illustrates. On the figure we show fixed effects for the hours of the day from a Poisson regression for the presence of panhandlers (with weather variables and block fixed effects). We also show histograms for the starting times of the walks. All three graphs peak in the late afternoon. Thus most of the time there are fewer than 8-10 panhandlers active in Downtown.

7.2 How Long Do Panhandlers Work? 
Although we did not identify individual panhandlers on the walks, several kinds of indirect information suggest that the average panhandling spell is short, probably only a few hours, and so the number of people who panhandle in a day or a week is likely a substantial multiple of 8-10.

We derive this rough estimate of the length of panhandling spells in two different ways. First, on several occasions we walked the same route twice in a few hours. In each pair of observations, we can find out how many block-fronts were occupied during the first walk but unoccupied during the second, and so we can estimate, very roughly, the hazard of a particular panhandling spell ending. We observed 13 panhandlers on the first of these pairs of walks, and 7 on those blockfronts in the second of these walks. So 46 percent of spells ended between walks. The average time between the starts of the two walks in a pair was 174 minutes, and so the half-life of a panhandling spell was about 3 hours.

Second, we have data about all calls and texts sent to 311, the New York City non-emergency hotline, about panhandling in Community District 1 . There are very few such calls-only 48 calls over three years. We know when the call or text was made, when the police responded, and what they found when they responded. In only 11 of the calls did the police find the situation that the callers had complained about, but responses often took a long time, since these were not priority calls.

To estimate turnover, we regressed the probability that the police would find the panhandler on the length of time it took to respond. We used a logit regression. The results indicated that if the police responded immediately, the probability was considerably less than one that they would have found the condition (this was an 
extrapolation because the quickest response took five minutes). If we assume that this shortfall for immediate response is entirely explained by erroneous calls, then we can calculate the implied half-life of panhandling spells. The implied half-life is 178 minutes, very similar to the implied half-life we found with repeated walks.

This similarity is almost certainly pure coincidence, since the samples are small and different, and we have imposed stringent assumptions on functional form. Since these are estimates of panhandling spells in the same location, they underestimate the length of panhandling spells simpliciter because a panhandler may try several locations in a spell. Since they require only some panhandler to be present later, not the one who was there earlier, they overestimate the length of panhandling spells in the same location.

A three-hour half-life implies an average spell of about 4.3 hours, if exit hazard rates are constant. Such a length is congruent with what panhandlers reported in conversations with us.

7.3 How Did the Number of Panhandlers Change Between 2014 and 2015?

Table 4 shows that the number of panhandlers did not increase between 2014 and 2015 in the raw data, despite the boom in Downtown Manhattan. This is contrary to our expectations. The apparent decline is not statistically significant, but intuition suggests that the boom should have caused a statistically significant increase in panhandling.

The question about whether panhandling increased is important because it can tell us about supply elasticity. If supply were highly elastic, general increases in 
generosity would be met by large increases in the number of panhandlers at any time, which might lead to fights over locations or tribute being paid to someone who controlled locations, or to reduced willingness of potential donors to give. Lord Mayor Doyle was effectively arguing that supply was elastic when he said that Prime Minister Turnbull erred by giving to Peter. But if supply were inelastic, the amount of panhandling would be relatively impervious to exhortations to donors and to small restrictions on allowable space.

Table 4, of course, is a crude estimate of the change in panhandling between the years because we did not sample the exact same-block fronts or at the exact same times or under the exact same weather conditions in the two years. In particular, figure 3 suggests that 2014 walks were concentrated earlier in the afternoon, a somewhat lighter period, than 2015 walks. Thus we will control for these differences to develop a more refined estimate of the average percentage change in panhandling between 2014 and 2015.

Specifically, we fit the following equation:

$$
E\left(\ln p_{b s y}\right)=\alpha+\beta Z_{s y}+\phi_{b}+\psi_{y}+\varepsilon_{b s y}
$$

where $p_{b s y}$ is the number of panhandlers on block front $\mathrm{b}$ at time $\mathrm{s}$ in year $\mathrm{t}, Z_{s y}$ is a vector of time-varying conditions at time s in year y (day of the week, hour of the day, week, rain, temperature and temperature squared), $\phi_{b}$ is a block-front fixed effect, and $\psi_{y}$ is a year fixed effect (since we take 2014 as the omitted category, this is essentially a dummy for 2015). The variable of interest is $\psi_{y}$ : the average regression-corrected percentage change in panhandling between 2014 and 2015. 
Dividing this by an estimate of the percent increase in the rate of return to panhandling would give a rough estimate of the labor supply elasticity. Recall from the theory section that with inter-location movement the average time series elasticity is likely to be less than the cross-section elasticity, but for most policy purposes, the time-series elasticity is more relevant.

Table 5 presents the results of estimating the equation. We cannot reject the hypothesis that the amount of panhandling did not change between 2014 and 2015 . (Table A-1 in the appendix shows comparable results with the logistic specification instead of the Poisson.) The point estimate with hour fixed effects (our preferred estimate) is slightly positive, but not close to being significant, and the sign changes if hour fixed effects are removed. The first impression from table 4 is essentially correct.

The obvious explanation for the constancy of panhandling is that the overall supply elasticity is small at both the extensive and intensive margins. However, several possible alternative explanations for this result suggest themselves.

The first possible alternative explanation is that the labor supply elasticity is zero or negative because the supply elasticity is great at intensive margin, and also large and negative at the intensive margin. Recall that some panhandlers described themselves as target earners. Even if the elasticity at the extensive margin is positive, the overall elasticity could be negative or zero if enough incumbent panhandlers are target earners. We call this the target earner hypothesis.

One implication of the target earner hypothesis is that panhandling should decrease the most on block fronts that experienced the greatest increase in rate of 
return. This is testable and we will test it in the next section. We would expect to see the greatest decreases in panhandling in the tourist zone. Another implication is that the number of different people panhandling should increase. We cannot test this because we did not use facial recognition software and attempt to identify panhandlers uniquely. Our impression is that the number of different people panhandling did increase between 2014 and 2015, and this is consistent with greater entropy in the location of panhandlers (which we show in section 7.5 below), but most impressions like this are not to be trusted.

The second possible alternative explanation is that on average panhandling became less lucrative between 2014 and 2015, not more lucrative. Beyond a certain throughput, additional pedestrians may hinder panhandling, not help it, because pedestrians are not able to slow down and pull money out of their pockets. If the increase in pedestrian flow is due to tourists, moreover, and tourists give less than workers and residents, the harm to panhandling will be greater. Panhandlers with a regular customer base are likely to be hit hardest: if their customers change routes to avoid the tourist influx they are lost entirely, and if they stay on the old route the congestion will make it harder for them to give. We call this the congestion hypothesis.

The testable implication of this story is block fronts that started with high initial pedestrian flow would be most likely to lose panhandlers, especially if they had large influxes of tourists. This would predict that the greatest decreases in panhandling would be along Broadway. The story also implies more new faces among panhandlers, because the losses would be greatest for the experienced. 
Another explanation is that the demand shock was offset by a supply shock: the prospects outside of panhandling for poor people improved and they turned to other pursuits. We cannot test this explanation with our data, but we find it implausible. Single adult shelter population rose 14.2 percent from July 2014 to July 2015 (NYC DHS 2016). The closest alternative to panhandling on the streets is panhandling on the subways (which is illegal); there was a massive increase in subway panhandling arrests in 2014 (Taylor 2014) and Police Commissioner Bratton kept pressure up in the subways in 2015, since reducing minor subway crime was a Bratton signature strategy. The redemption price of recycled cans was unchanged. If there was a supply shock, it is more likely that it was positive (more panhandlers on the street) than negative.

A final possible alternative explanation is that panhandling could not expand because there was no room; it was sharply constrained by the availability of good locations. We will examine this possibility below in section 7.5 below.

\subsection{Zone Results}

Our next step is to disaggregate the change in panhandling by zone. The different explanations have different implications for how the zones should have changed, and so we can learn more about what happened by looking at zones.

The simple way of doing this is to disaggregate block fronts by zone, and to compare average numbers of panhandlers observed in 2014 and 2015. This is essentially table 4, but with block fronts sorted by zone rather than by walk (and missing observations treated slightly differently). The results are in table 6 . 
Average panhandlers per block front increased in the tourist zone and the other areas, but decreased substantially on Broadway.

Of course, because the 2015 walks differed from the 2014 in many ways (especially time of day), we need to correct for differences. To do this, we remove the dummy variable for 2015 from equation (1), and interact this dummy variable with dummy variables for each of the three zones. We also drop the block-front fixed effects. So the coefficient on the tourist zone dummy interacted with the 2015 dummy, for instance, gives the average percentage change in panhandling in the tourist zone between 2014 and 2015. Table 7 presents the key results. (Table A-2 in the appendix shows comparable results with the logistic specification instead of the Poisson.)

Table 7 shows that the increase in tourism is associated with a large and statistically significant increase in panhandling in the tourist zone (the logit specification shows an increase, but not statistically significant). We can reject the target earner hypothesis. The congestion hypothesis receives minimal support, as the Broadway coefficient is slightly negative, but insignificant (and the raw data show a large decrease on Broadway).

The obvious story is that the rise in tourism attracted more panhandlers, possibly at the expense of Broadway (this is an alternative to the congestion hypothesis to explain the possible decline in Broadway panhandling). The supply elasticity within Downtown is positive. Since annual visitors increased by about 30 percent and panhandling within the tourist zone increased by about 70 percent, the elasticity may be greater than one. But since overall panhandling probably did not 
increase Downtown, most of the gain in tourist zone panhandling was relocation from Broadway, not new panhandlers.

\subsection{Locations and Heterogeneity}

How different are the rates of return to the locations that panhandlers might use downtown? Are a lot of places pretty much the same, or are there just a few places that suitable for panhandling, with other locations distinctly inferior?

This question is important for our inquiry into why aggregate panhandling did not increase in response to the 2015 demand shock—perhaps the added locations that would have had to be occupied to accommodate an influx of panhandlers were so inferior to existing locations that the demand shock was not big enough to make them attractive to many panhandlers. The panhandling response would have been constrained by the absence of suitable locations.

The question is also important for our broader inquiry into who benefits from panhandling. If a few locations are superior to all others, then control of these locations could generate rent. Panhandlers themselves might not be the ultimate beneficiaries of donors' generosity, because they might have to share it with whoever controlled these locations, and at the very least we would expect to see contention and conflict. On the other hand, if a lot of locations are pretty much the same, then we would expect to see little fighting, and the donations that panhandlers get are likely to stay with them.

Heterogeneity also matters for policy because many policy proposals seek to limit the number and type of locations where panhandling occurs. The welfare implications of these policies depend in part on whether the locations prohibited 
have good substitutes, and the market implications depend on the heterogeneity of the remaining locations. We explore these issues in the companion paper.

Notice that for all purposes, the similarity of locations matters only for locations that are sometimes occupied, or are on the margin of occupation. Since only 8-10 locations are occupied at an average time, how good the $70^{\text {th }}$ best location is doesn't matter.

We have already seen some indirect evidence that locations are fairly homogenous within these bounds. That panhandlers are peaceful and atomistic suggests little heterogeneity among locations-but peace and atomism could have other explanations, too (panhandling might just attract individuals who are pleasant and laid-back, for instance). Similarly, the expansion of panhandling in the tourist zone suggests that in 2014 panhandling was not seriously constrained by the availability of decent locations.

In this section we try to understand how heterogeneous locations are. This is hard because we are concerned with heterogeneity in the rate of return that a standard panhandler would realize, and we do not observe this variable. Instead, we take two indirect approaches: expert evaluations, and the revealed preferences of panhandlers.

\subsubsection{Expert Evaluations}

In 2016, an experienced busker examined all of the block-fronts and assessed how attractive they were for panhandling (and busking). He sorted them into several different ordered categories, in two different ways. The first was intuitive: his unstructured reaction after looking at the block-front. The second was 
structured: he assessed the block-front on four criteria (space, circulation, construction and security) and gave it a score by aggregating the scores on the criteria.

The two assessments are consistent. The correlation between the intuitive score (as ordered integers) and the structured summary score was 0.81 . The Spearman rank order correlation was also 0.81 . We also regressed the intuitive score on the criteria. All of the criteria have positive and significant effects on the intuitive score.

Finally, we compared the expert assessments with results of the walks. First we ran the following Poisson regression:

$$
E\left(\ln p_{b t}\right)=\alpha+\beta X_{t}+\varepsilon_{b t}
$$

Where the controls in $X_{t}$ were categorical dummies for time of day, day of week, year, and rain; and continuous variables for temperature and temperature squared. Then we added categorical variables for the expert assessments, both intuitive and structured. The results are in table 8 (was table 4).

The first panel of table 8 shows that the intuitive assessments accurately predict the presence panhandlers: significantly more panhandlers are observed in higher ranked locations. However, there is very little difference between the two highest categories. The second panel shows a similar effect when the total scores from the structured assessments: locations with higher scores have more panhandlers. All of the categories with scores above 3 have significantly more panhandlers than categories with scores below 3 . There is a difference that is 
almost significant, however, between locations with the highest possible score, 6 , and locations with scores in the 3-5 range.

Thus both the intuitive and structured evaluations appear to be reasonable descriptions of how attractive locations are.

The intuitive evaluations suggest that locations are fairly homogenous in the relevant range. Table 9 shows the number of locations by intuitive evaluation. Table 8 shows that the "good" and "very good" categories are not much different, and table 9 shows that a total of 21 block-fronts were "good" or "very good." With 8-10 panhandlers at an average time, it seems unlikely that all the good and very good block-fronts are ever occupied simultaneously.

Similarly, with the structured evaluations, 12 locations have the highest possible score of 6 , and there does not appear to be much difference among the next 48 locations with scores in the 3-5 range. Based on these measures, it does not appear that panhandlers have any reason to fight over locations.

\subsubsection{Revealed Preferences}

We can also look at measures of heterogeneity based directly on panhandler behavior. The basic insight from the model in section 3 is that if two locations differ greatly in the rate of return, it should be very rare for the less lucrative one to be occupied while the more lucrative one is empty. But if rates of return are fairly similar, the less lucrative one will often be occupied when the more lucrative one is empty.

The first way we look at revealed preferences is simply to record the probability that a block-front will be occupied by at least one panhandler when it is 
observed. For each of the 71 block-fronts we calculate this probability in each year, and in figure 4 we display it. For each year, we array block-fronts from the most popular to the least (if panhandlers had to pay to rent a block-front, this would resemble a downward-sloping demand curve). Figure 4 shows that panhandling was much less concentrated in 2015 than in 2014. In 2014 only four locations were occupied more than $60 \%$ of the times that we surveyed them and in 2015 , none were. In other words, even the very best locations were often unoccupied in both years. In 2014, popularity shows something of a cliff in the 8-14 range, but this range is very close to flat in 2015. In both years, there were many block fronts (46 in 2014 and 17 in 2015) where we never saw a panhandler, even though we chose these block-fronts in the belief that they were the places where panhandlers would most readily be found.

Raw probabilities of occupation, however, do not control for changes in time and weather. Therefore figure 5 is the same as figure 4, but shows the block-front fixed effects from equation (1), also arrayed from biggest to smallest. (Since many block-fronts in each year have no sightings of panhandlers, many block-fronts have uniformly negative fixed effects. The default in this case is a particular block on which no panhandlers were seen in either year, and so all the fixed effects are nonnegative.) The pattern in figure 5 resembles that in figure 4, with no discontinuities in the range of 8-10 block fronts.

Thus all results point to moderate levels of heterogeneity, and less heterogeneity in 2015 than in 2014. Locations differ, but many of them don't differ that much. 


\subsection{Interdependence}

A final question about locations is whether the presence of panhandlers at one location influences their presence at others. Included in this question is whether panhandlers tend to move between locations, as our finding of an increase in panhandling in the tourist zone suggested. We concentrate on influences between locations that are close to each other on the same route. Obviously, influences could be more complex than this, but if there are any influences at all, they are likely to be present at this level. More complex influences, and those that operated over a greater difference, would also be harder to find-in part, because we never observe two locations far from each other simultaneously, because foot travel takes time.

On each route we divide block fronts into those that are interior (they have a neighbor on each side) and those that are not (the first and last, which have only one neighbor each). For each block front $b$, let $n_{b}=1$ if $b$ is interior, zero otherwise. If block front $\mathrm{b}$ is interior, let $\mathrm{dbt}$ be the number of neighboring block fronts that are occupied on day $\mathrm{t}$; the possible values are 0,1 , and 2 . If the block front is not interior, let $\mathrm{D}_{\text {it }}$ be the number of neighboring block fronts occupied on day $\mathrm{t}$; possible values are 0 and 1.

Then we fit equations of the following form:

$$
\ln p_{b t}=\alpha+\beta X_{t}+\gamma E_{b}+\delta n_{b} d_{b t}+\eta\left(1-n_{b}\right) D_{b t}+\varepsilon_{b t}
$$

where $E_{b}$ is a vector of expert evaluations (both intuitive and structured in different equations) of how attractive block front b is. Our coefficients of interest are $\delta$ and $\eta$. 
Results of this equation can be found in column 1 of table 10 . An interior block-front is less likely to have a panhandler on it if neighboring block-fronts have panhandlers on them. This result is borderline significant when the structured evaluation is used, but not when the intuitive evaluation is used. For terminal block fronts, effects are imprecisely estimated and not stable (possibly because there are few of them). So there is some weak evidence that interdependence matters, and that it works in the negative direction.

Interdependence like this is consistent with either movement (section 3.2) or externalities (section 3.3). The strength of the movement effect, however, depends on how relatively lucrative the neighboring locations are, while the externality effect does not. To try to see how much of the interdependence effect is movement, we add another two variables. The variable rbt is the average of the intuitive rankings of location b's two neighbors for interior b, and $\mathrm{Rbt}$ is the intuitive ranking of location b's single neighbor, if $\mathrm{b}$ is not interior. Then we estimate the equation:

$$
\ln p_{b t}=\alpha+\beta X_{t}+\gamma E_{b}+\delta n_{b} d_{b t}+\eta\left(1-n_{b}\right) D_{b t}+\phi n_{b} r_{b t}+\psi\left(1-n_{b}\right) R_{b t}+\varepsilon_{b t}
$$

The results are column 2 of table 10. With the structured evaluations, more attractive neighbors reduces the presence of panhandlers at a block-front significantly. The same is true for intuitive evaluations, but the result is not significant. With structured evaluations, controlling for neighbor quality makes the negative sign on the presence of neighbors for the structured evaluation significantly negative. Thus it seems that the interdependence effect is primarily from movement: panhandlers leave worse locations when better locations are 
nearby (or never start working on worse locations when they can see a better one). This is consistent with the picture of movement between locations.

\section{Conclusion}

So it seems that Prime Minister Turnbull had a more accurate model of panhandling than Lord Mayor Doyle, at least if Inner Melbourne is like Downtown Manhattan. Turnbull's example was unlikely to trigger a deluge of panhandlers into Melbourne, although if it inspired a lot of pedestrians it might move a few panhandlers from Flinders Street to Collins Street. A single Australian prime minister is not likely to be more powerful than the tallest building in the Western Hemisphere. The donation mattered to Peter, and that was about it, and it probably did not matter much to Peter after he ate lunch.

The picture of Downtown panhandlers that emerges from our study is that of a small group of men (and a few women) who are either highly unusual (for consistent panhandlers) or at an unusual point in their lives (for sporadic panhandlers). They are not unusual in their poverty, but probably in their willingness to withstand the stigma, rejection, uncertainty, and physical hardships that serious panhandling entails. No doubt some people at the margin could be coaxed into panhandling by higher pecuniary returns, or convinced to extend their sojourn into panhandling a little longer. But the number of people at the extensive margin is small (at this time and place), and any extensive margin effects may be offset by target-earning behavior among infra-marginal panhandlers. 
These men and women are not irrational or impervious to their surroundings. They responded to the tourist influx by moving to locations that became more attractive and in general they are less likely to panhandle at a worse location when a better one is nearby. But they are not instantaneous omniscient maximizers.

Because the number of people who want to panhandle, even at the best times and places, is small, space is effectively free. Supply at zero price exceeds demand. Because space is free, so is courtesy, and so is abiding by norms. There is little surplus that a monopolist could extract, either by controlling locations or restricting labor supply. So there is no monopolist.

We could have estimated elasticities more precisely if we had more observations and better information about pedestrian flows and generosity. That would have made for a better paper. Still, we can be pretty sure that the effect of the boom in Downtown was small in practical terms. Even if the elasticity of aggregate panhandling with respect to spending power is unity—which is unlikely-the boom would have added only about one panhandler at the average time we observedand this is in an economy the size of Latvia's.

The difficulty we had in estimating this elasticity, however, illustrates another reason why it is probably small: the panhandling environment is very noisy. Variations of 10 percent or more in pedestrian flows at the same place and time of the week are common in the DoT data between May and September in the same year. Within pedestrian flows the rate of generosity probably varies too. And even if the rate of giving per 1000 pedestrians is constant, random variation in actual 
donations will be large. Many block-fronts may go weeks without a panhandler sampling from them. So while it may be the case that in the limit panhandlers will have enough time to adjust to a one-time shock to one of the basic parameters, the limit may be far away, and other shocks may intervene. The speed of adjustment may be very slow.

The speed of academic learning about panhandling as an industry, however, may be faster. This paper is a first step. A companion paper (Dordick et al. 2017) explores policy implications and shows different ways in which this paper's results affect optimal policy. Another companion paper will look more deeply at how panhandlers view their world and each other, and adjust to both.

Beyond the current project, the need to learn about other environments and other shocks is obvious; so is the need to engage in policy experiments. Recent literature (e.g., Della Vigna et al 2012, Trachtman et al 2015, and Andreoni et al 2016) has taught us a great deal about donors and non-donors to organized charities; we need to learn similar things about donors to panhandlers.

After Prime Minister Turnbull gave Peter the fiver, he told the media and the Committee for Economic Development about his plans to prepare a budget bill that the opposition had said it could support; it was his first major economic address following the election and revealed important information about the management of Australia's economy. This story did not go viral. Even though Peter is not traditional click-bait like kittens and Kardashians, the public found his story much more interesting than the prime minister's major economic address.

Social scientists should learn something from this incident. 


\section{References}

Andreoni, James, Justin M. Rao, and Hannah Trachtman, 2016, "Avoiding the Ask: A field Experiment on Altruism, Empathy, and charitable Giving, "Journal of Political Economy, forthcoming.

Adriaenssens, Stef and Jef Hendrickx, 2011, "Street-Level Informal Economic Activities: Estimating the Yield of Begging in Belgium," Urban Studies 48(1): 23-40.

Bose, Rohit J. and Stephen W. Hwang, 2002, "Income and Spending Patterns among Panhandlers," Canadian Medical Association Journal, 167 (5): 477-479.

Butovskaya, M., F. Kemp, I. Diakonov, and A. Smirnov, 2004, "Urban Begging and Ethnic Nepotism in Russia: An Ethological Pilot Study," Pp. 27-52, Welfare, Ethnicity and Altruism: New Findings and Evolutionary Theory, edited by F. Salter. London: Frank Cass.

Della Vigna, S., J. List, and U. Malmendier, 2012, "Testing for Altruism and Social Pressure in Charitable Giving," Quarterly Journal of Economics 127(1): 1-56.

Deuneir, Mitchel, 1999, Sidewalk. New York: Ferrar, Strauss and Giroux.

Dobbin, Marika, 2016, 'A Little Stingy': Homeless Man Tells of Brush with Millionaire Prime Minister, Sydney Morning Herald. Retrieved August 19. (http://www.smh.com.au/federal-politics/political-news/a-little-stingyhomeless-man-tells-of-brush-with-millionaire-prime-minister-20160819gqwwun.html).

Dordick, Gwendolyn A., 1997, Something Left to Lose: Personal Relations and Survival among New York's Homeless. Philadelphia: Temple University Press.

Dordick, Gwendolyn A. and Brendan O'Flaherty, 2014, "Panhandling in Downtown Manhattan: A Preliminary Analysis." CUNY Graduate Center, October 22, 2013.

Dordick, Gwendolyn A. Brendan O’Flaherty, Unpublished Manuscript. Jakob Brounstein, and Srishti Sinha, 2017, Policy for Panhandling: How to Encourage Good Panhandling and Discourage Bad.

Downtown Alliance, 2016, “Lower Manhattan's Largest Tenants in 2015." Retrieved June 18, 2016 (http://www.downtownny.com/sites/default/files/research/LM\%20Larges t\%20Tenants\%202015.pdf).

Downtown Alliance, 2015, Lower Manhattan Indicators Q3 2015. Retrieved June 18, 2016

(http://www.downtownny.com/sites/default/files/research/Q3\%2015 LM \%20Fact\%20Sheet.pdf).

Ellickson, Robert C., 1991, Order Without Law: How Neighbors Settle Disputes. Cambridge: Harvard University Press.

Ellickson, Robert C., 1996, "Controlling Chronic Misconduct in City Spaces: Of Panhandlers, Skid Rows, and Public Space Zoning," Yale Law Journal 105 (5): $1165-1248$. 
Fogel, Robert W., 1994, "Economic Growth, Population Theory, and Physiology: The Bearing of Long-Term Processes on the Making of Economic Policy," American Economic Review 84(3): 369-95.

Goldstein, Brandt J., 1993, "Panhandlers at Yale: A Case Study in the Limits of Law," Indiana Law Review 27: 295-360.

Green, Dennis, 2015, "New Yorkers Will Pay $\$ 1$ Million for Something Most Americans Get for Free." Business Insider, August 21. Retrieved August 30, 2016 (http://www.businessinsider.com/new-york-city-welcomes-the-1million-parking-space-2015-8).

Hauser, Christine, 2016, Australian Premier's Handout Spurs Debate on Best Way to Help Homeless People, New York Times, Retrieved August 19, 2016 http://www.nytimes.com/2016/08/20/world/australia/malcolm-turnbullhandout-spurs-debate-on-best-way-to-help-homeless-people.html? $r=1$ ).

Lankenau, Stephen E., 1999a, "Panhandling Repertoires and Routines for Overcoming the Nonperson Treatment," Deviant Behavior 20(2): 183-206.

Lankenau, Stephen E.,, 1999b, "Stronger Than Dirt: Public Humiliation and Status Enhancement among Panhandlers," Journal of Contemporary Ethnography 28(3): 288-318.

Lee, Barrett, and Chad R. Farrell, 2003, Buddy, can you spare a dime? Homelessness, panhandling, and the public, Urban Affairs Review 38 (January): 299-324.

Lu, H., 1999, "Becoming Urban: Mendicancy and Vagrants in Modern Shanghai," Journal of Social History 33(1): 7-36.

Murdoch, A., 1994, We Are Human, Too: A Study of People Who Beg. London: Crisis.

New York City Department of City Planning, 2016, Community Portal. Retrieved June 18, 2016 (http://www1.nyc.gov/site/planning/community/communityportal.page).

New York City Department of City Planning, 2006, New York City Pedestrian Level of Service Study Phase 1: April.

(http://www1.nyc.gov/assets/planning/download/pdf/plans/transportation/td fu llpedlosb.pdf).

New York City Department of Homeless Services, 2016a, DHS Data Dashboard FY 2016. Retrieved August 29, 2016 (http://www1.nyc.gov/assets/dhs/downloads/pdf/dashboard/dhs data da shboard charts FY-2016-Q2.pdf).

New York City Department of Homeless Services, 2016b, "2016 Federally Mandated HOPE Count Finds 12 Percent Decline in Street Homeless on the Night of the Count." Retrieved August 29, 2016 (http://www1.nyc.gov/office-of-themayor/news/408-16/2016-federally-mandated-hope-count-finds-12percent-decline-street-homeless-the-night-the).

New York City Department of Transportation, 2016, Bi-annual Pedestrian Counts, retrieved July 7, 2016 at http://www.nyc.gov/html/dot/html/about/datafeeds.shtml\#Pedestrians O'Flaherty, Brendan, 1996, Making Room: The Economics of Homelessness. Cambridge: Harvard University Press.

September 11 Museum, 2014, Annual Report. Retrieved August 28, 2016 (http://2014.911memorial.org/). 
---, 2015, Annual Report. Retrieved August 28, 2016 (http://2015.911memorial.org/\#visitors).

Smith, P.K., 2005, "The Economics of Anti-Begging Regulations," American Journal of Economics and Sociology 64(2): 549-77.

Snow, David and Leon Anderson, 1993, Down on Their Luck: A Study of Homeless Street People. Berkeley: University of California Press.

Snow, David and Leon Anderson, 2003, "Street People," Contexts, 2(1): 12-17.

Taylor, Matt, 2014, "Why are New York City Cops Cracking Down on Subway Panhandlers?" Vice, April 2. Retrieved August 30, 2016 (http://www.vice.com/read/is-going-after-subway-panhandlers-smartpolicing-strategy).

Trachtman, Hannah, A. Steinkruger, M. Wood, A. Wooster, J. Andreoni, J. J. Murphy, and J. M. Rao, 2015, "Fair Weather Avoidance: Unpacking the Costs and Benefits of 'Avoiding the Ask,' Journal of the Economic Science Association: 17. 
Figure 1: Map of Routes

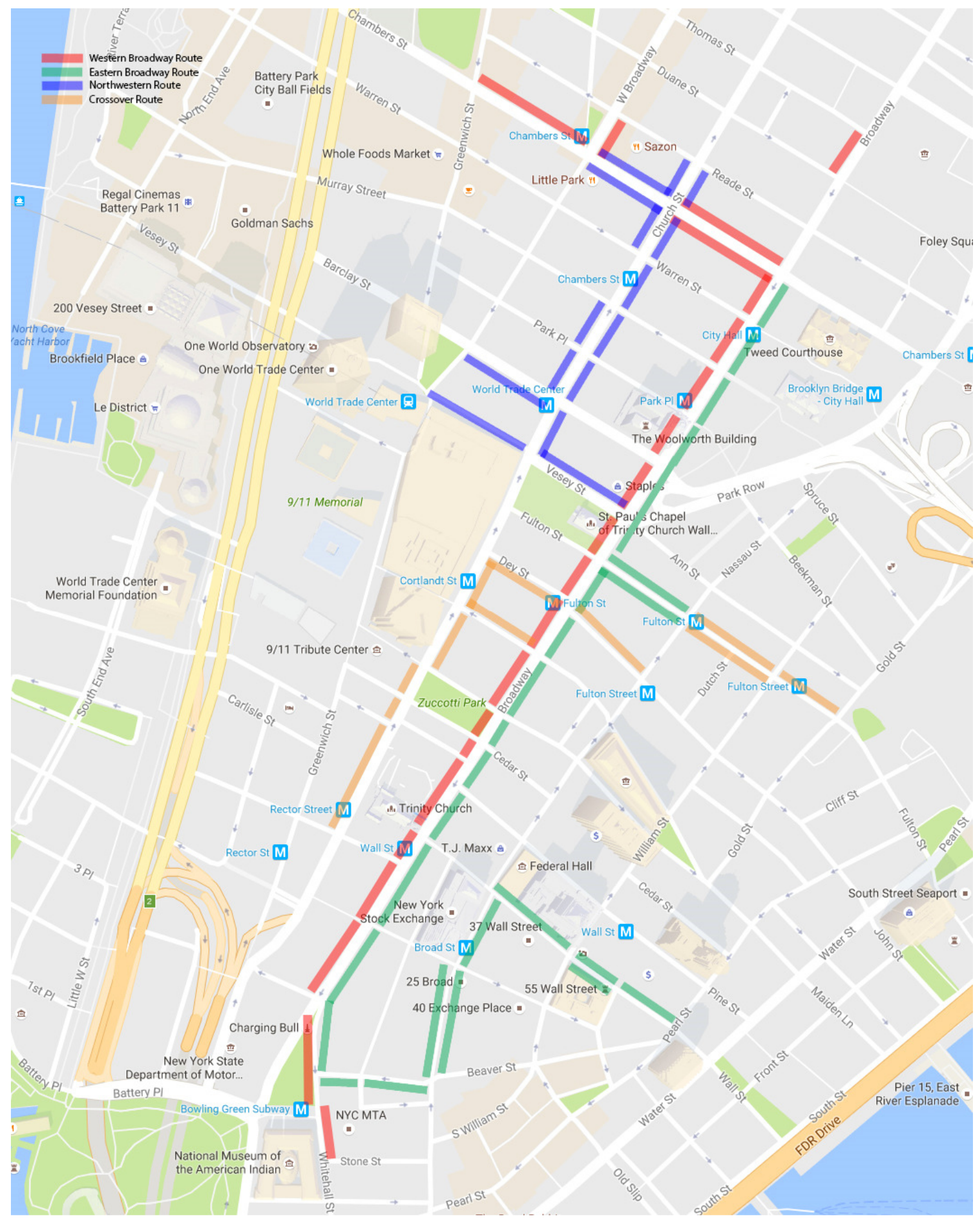




\section{Figure 2: Map of Zones}

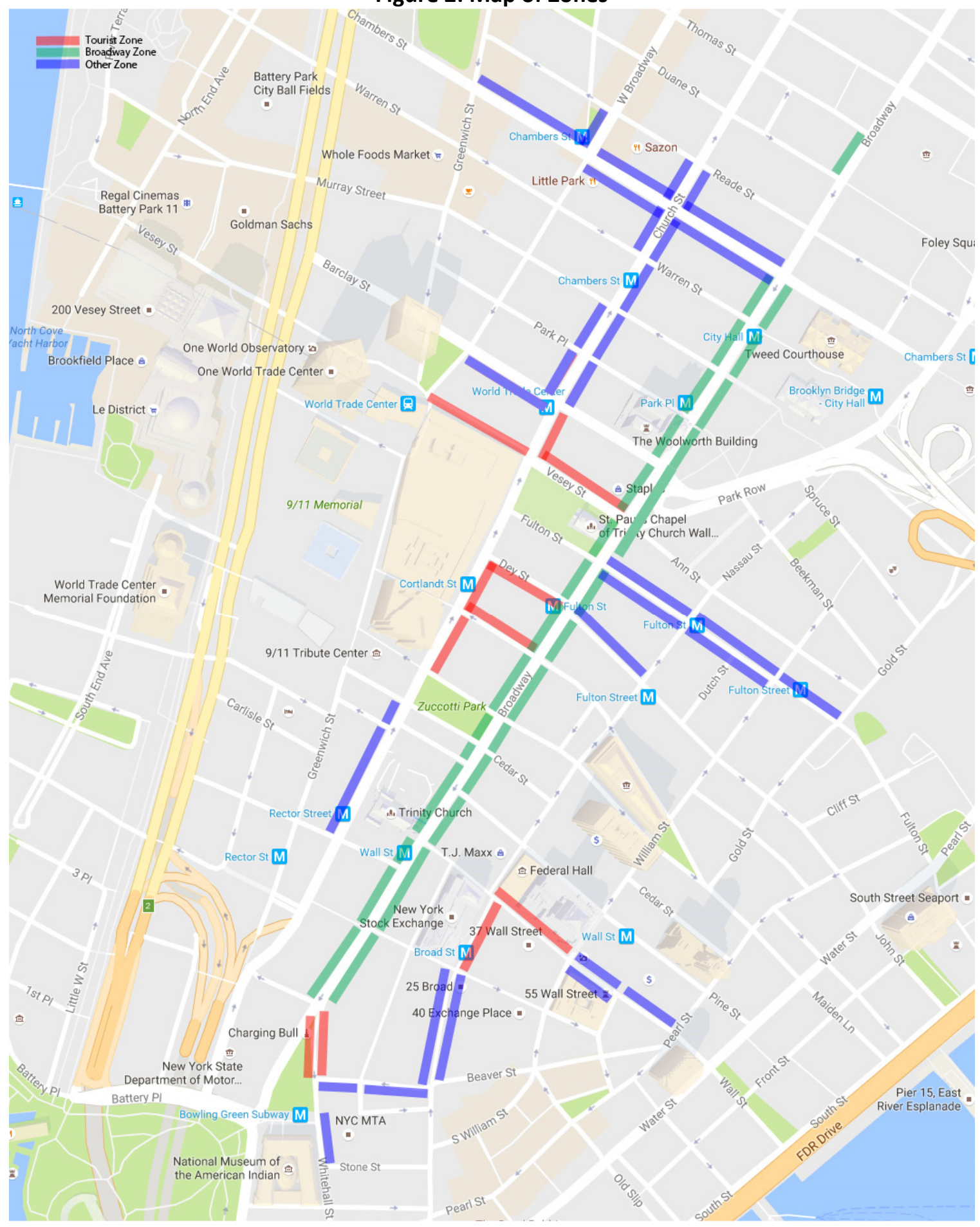


Figure 3: Walk Starting Times

\section{Walk Frequency by Hour}
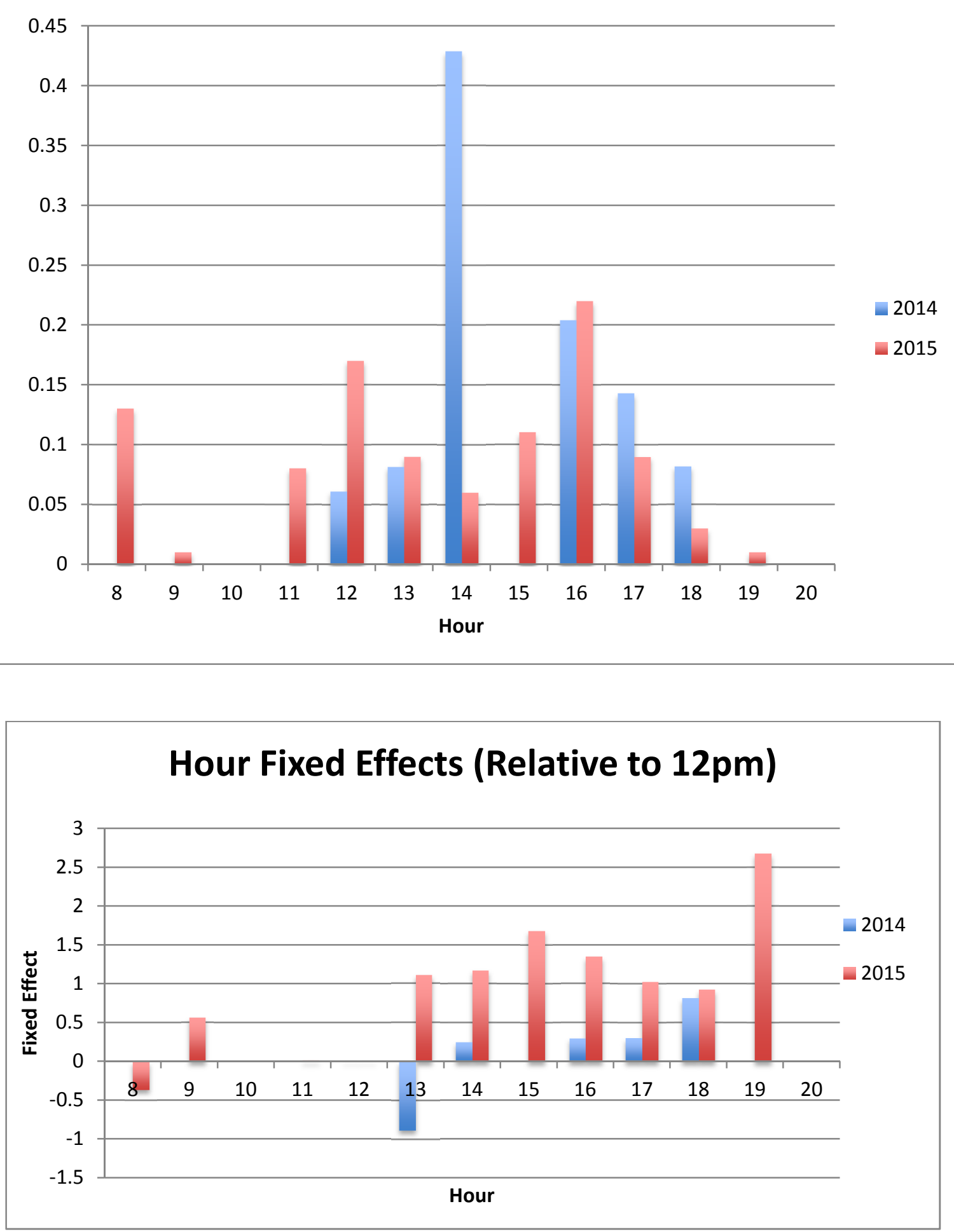
Figure 4: Locations by Probability of Occupation

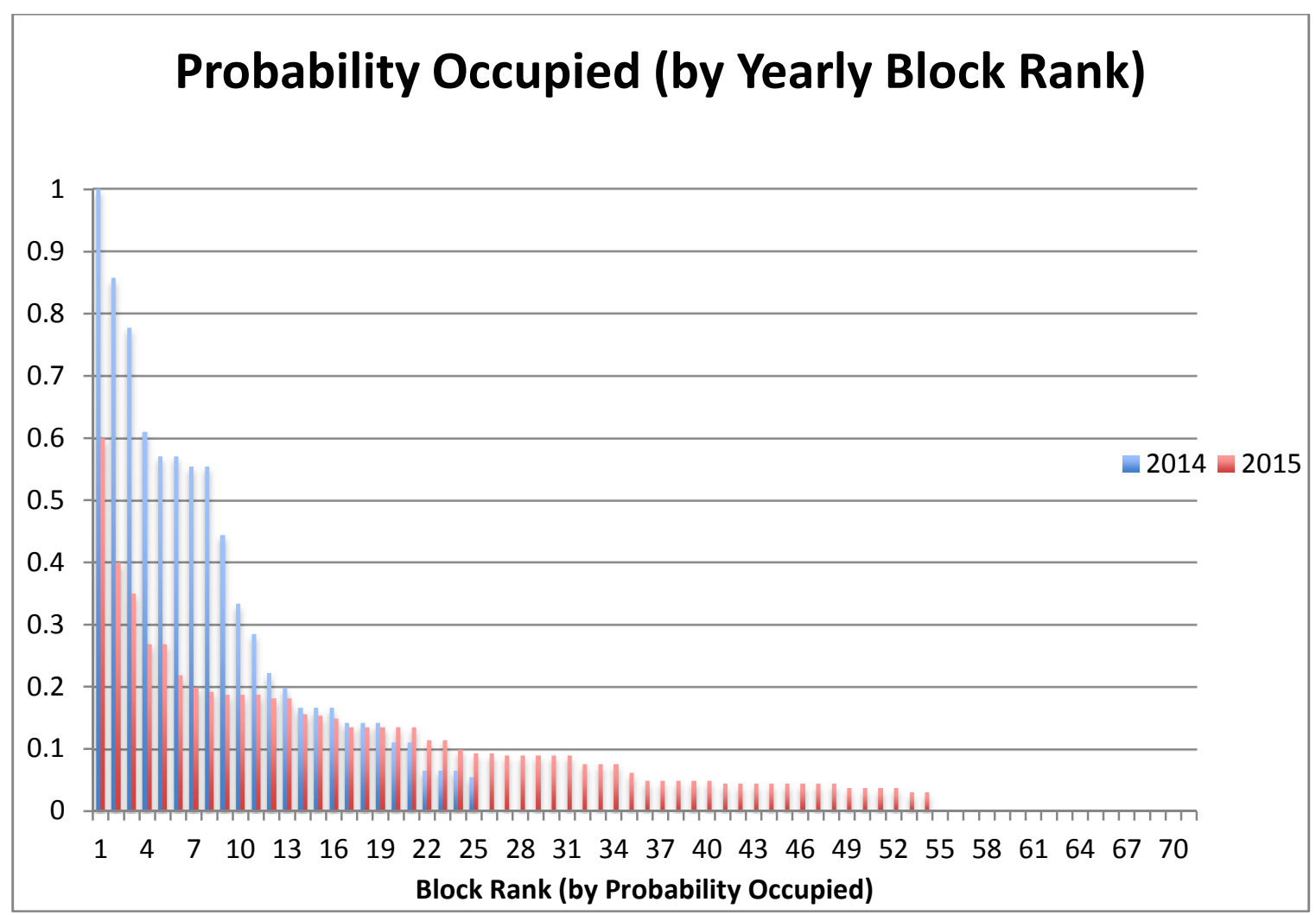


Figure 5: Locations by Fixed Effects

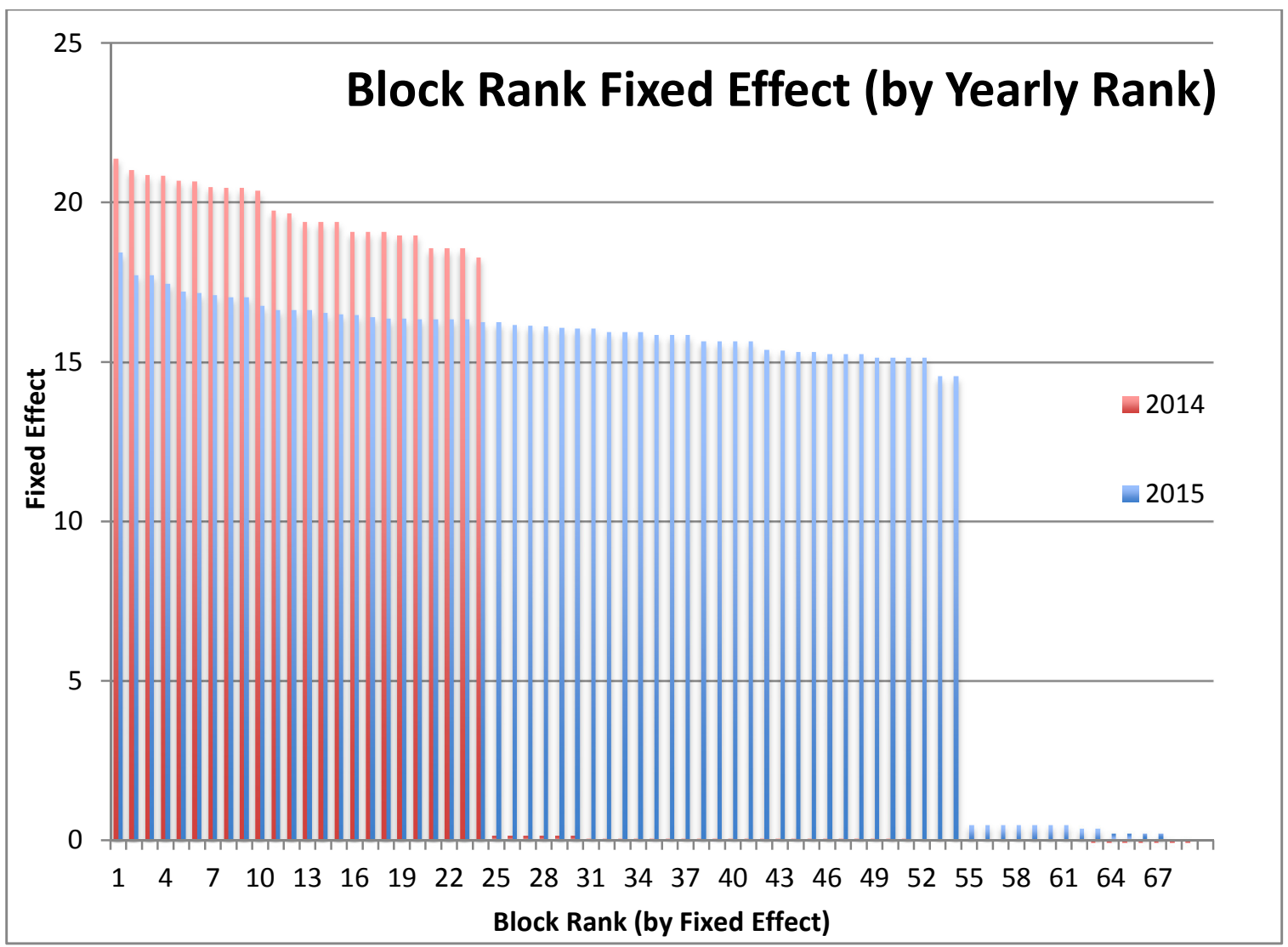

Note: Block fixed effect yearly rank chart, with block fixed effects relative to block 5, which was empty for all observations in both years. 
Table 1: Indicators of Growth in Downtown Manhattan, summer 2014 to summer 2015

\begin{tabular}{llll} 
& $\mathbf{2 0 1 4}, \mathbf{3}^{\text {rd }}$ quarter & $\mathbf{2 0 1 5}, \mathbf{3}^{\text {rd }}$ quarter & \% increase \\
\hline Annual visitors & 9.6 million & 12.4 million & $29.2 \%$ \\
Hotel rooms & 4,681 & 5,225 & 11.6 \\
Annual spending power & $\$ 5.2$ billion & $\$ 5.8$ billion & 11.5 \\
Student residences & 1,850 & 2,620 & 41.6 \\
Average daily PATH riders & 34,510 & 40,411 & 17.1 \\
Average daily ferry riders & 85,162 & 91,965 & 8.0 \\
Average weekday subway & 310,254 & 344,280 & 11.0 \\
Commercial square footage & 85.6 million & 87.8 million & 2.6 \\
Private sector employees & 224,806 & $225,038^{*}$ & 0.1 \\
Number of residents & 61,000 & 62,000 & 1.7 \\
& & &
\end{tabular}


Table 2: New York City Department of Transportation Pedestrian Counts, 2014 and 2015

\begin{tabular}{c|ccc|ccc} 
& \multicolumn{7}{c}{ Weekdays between 4 and 7 pm } \\
Block & $\mathbf{2 0 1 4}$ & $\mathbf{2 0 1 5}$ & \% change & $\mathbf{2 0 1 4}$ & Sep. 2015 & \% change \\
\hline $\begin{array}{c}\text { Broadway, from } \\
\text { Morris to } \\
\text { Exchange }\end{array}$ & 12,666 & 14,507 & +14.5 & 16,251 & 13,111 & -19.3 \\
\hline $\begin{array}{c}\text { Chambers, from } \\
\text { W. B'w'y to } \\
\text { Greenwich }\end{array}$ & 10,248 & 9689 & -5.5 & 10,478 & 9256 & -11.7 \\
\hline $\begin{array}{c}\text { Chambers, from } \\
\text { W. B'w'y to } \\
\text { Greenwich }\end{array}$ & 10,248 & 9689 & -5.5 & 10,478 & 9256 & -11.7 \\
\hline $\begin{array}{c}\text { Fulton, from } \\
\text { Broadway to } \\
\text { Nassau }\end{array}$ & 7732 & 8002 & +3.5 & 7212 & 7037 & -2.4 \\
\hline $\begin{array}{c}\text { Fulton, from } \\
\text { Broadway to } \\
\text { Nassau }\end{array}$ & 7732 & 8002 & +3.5 & 7212 & 7037 & -2.4 \\
\hline $\begin{array}{c}\text { Trinity, Rector to } \\
\text { Thames }\end{array}$ & 4504 & 5964 & +32.4 & 5095 & 5592 & +9.75 \\
\hline
\end{tabular}

Source: New York City Department of Transportation, "Bi-annual pedestrian index." Accessed at http://www.nyc.gov/html/dot/html/about/datafeeds.shtml\#Pedestrians 
Table 3a: Total Metrocard Swipes

\begin{tabular}{lrrr} 
& $\mathbf{2 0 1 4}$ & $\mathbf{2 0 1 5}$ & $\mathbf{\%}$ change \\
\hline TOTAL & $\mathbf{2 5 3 7 6 6 5 4}$ & $\mathbf{2 6 4 1 0 2 8 3}$ & $\mathbf{4 \%}$ \\
TOURIST ZONE & & & \\
RECTOR STREET-CHURCH STREET & 219139 & 491594 & $124 \%$ \\
BROAD STREET \& WALL STREET & 434776 & 476297 & $10 \%$ \\
BOWLING GREEN \& BROADWAY & 591555 & 423479 & $-28 \%$ \\
RECTOR STREET-GREENWICH ST & 863343 & 752454 & $-13 \%$ \\
BOWLING GREEN \& BATTERY PL & 2078247 & 1826167 & $-12 \%$ \\
WHITEHALL STREET & 1624472 & 2108126 & $30 \%$ \\
PA-PATH WORLD TRADE CNTR & 1116111 & 1446314 & $30 \%$ \\
SUBTOTAL & 6927643 & $\mathbf{7 5 2 4 4 3 1}$ & $\mathbf{9 \%}$ \\
& & & \\
NON-TOURIST ZONE & & & \\
BROOKLYN BRIDGE & 2844231 & 2694655 & $-5 \%$ \\
CHAMBERS STREET & 1643002 & 1678013 & $\mathbf{2 \%}$ \\
PARK PLACE & 4121366 & 4396832 & $\mathbf{7 \%}$ \\
CITY HALL & 246435 & 486265 & $97 \%$ \\
FULTON STREET & 3046362 & 3607124 & $18 \%$ \\
WALL STREET & 4099723 & 3777552 & $-8 \%$ \\
FULTON \& WILLIAM STREETS & 2447892 & 2245411 & $-8 \%$ \\
SUBTOTAL & $\mathbf{1 8 4 4 9 0 1 1}$ & $\mathbf{1 8 8 8 5 8 5 2}$ & $\mathbf{2 \%}$
\end{tabular}


Table 3b: Full-Fare Metrocard Swipes

\begin{tabular}{lrrr} 
& $\begin{array}{r}\mathbf{2 0 1 4} \\
\text { (May } \mathbf{3 1} \text { to } \\
\text { Sep 5) }\end{array}$ & $\begin{array}{r}\text { 2015 } \\
\text { (May 30 to }\end{array}$ & \\
& Sep 4) & \% change \\
\hline TOTAL & $\mathbf{1 2 4 6 1 0 5 5}$ & $\mathbf{1 2 8 6 6 4 3 7}$ & $\mathbf{3 \%}$ \\
TOURIST ZONE & & & \\
RECTOR STREET-CHURCH STREET & 97719 & 221306 & $126 \%$ \\
BROAD STREET \& WALL STREET & 189536 & 196072 & $3 \%$ \\
BOWLING GREEN \& BROADWAY & 276290 & 196277 & $-29 \%$ \\
RECTOR STREET-GREENWICH ST & 424233 & 362013 & $-15 \%$ \\
BOWLING GREEN \& BATTERY PL & 901884 & 778760 & $-14 \%$ \\
WHITEHALL STREET & 835889 & 993726 & $19 \%$ \\
PA-PATH WORLD TRADE CNTR & 1038007 & 1352369 & $30 \%$ \\
SUBTOTAL & $\mathbf{3 7 6 3 5 5 8}$ & $\mathbf{4 1 0 0 5 2 3}$ & $\mathbf{9 \%}$ \\
& & & \\
NON-TOURIST ZONE & & & \\
BROOKLYN BRIDGE & 1276154 & 1173119 & $-8 \%$ \\
CHAMBERS STREET & 744702 & 754978 & $1 \%$ \\
PARK PLACE & 2142313 & 2269199 & $6 \%$ \\
CITY HALL & 110351 & 214503 & $94 \%$ \\
FULTON STREET & 1477030 & 1696082 & $15 \%$ \\
WALL STREET & 1894839 & 1718342 & $-9 \%$ \\
FULTON \& WILLIAM STREETS & 1052108 & 939691 & $-11 \%$ \\
SUBTOTAL & $\mathbf{8 6 9 7 4 9 7}$ & $\mathbf{8 7 6 5 9 1 4}$ & $\mathbf{1 \%}$ \\
& & &
\end{tabular}


Table 3c: 30-Day Metrocard Swipes

\begin{tabular}{lrrr} 
& $\begin{array}{r}\mathbf{2 0 1 4} \\
\text { (May 31 to } \\
\text { Sep 5) }\end{array}$ & $\begin{array}{r}\mathbf{2 0 1 5} \\
\text { (May 30 to } \\
\text { Sep 4) }\end{array}$ & \% change \\
\hline TOTAL & $\mathbf{6 6 1 6 1 5 0}$ & $\mathbf{6 7 0 3 9 7 1}$ & $\mathbf{1 \%}$ \\
TOURIST ZONE & & & \\
RECTOR STREET-CHURCH STREET & & & \\
BROAD STREET \& WALL STREET & 131938 & 1439 & $127 \%$ \\
BOWLING GREEN \& BROADWAY & 107596 & 76816 & $-29 \%$ \\
RECTOR STREET-GREENWICH ST & 220931 & 193272 & $-13 \%$ \\
BOWLING GREEN \& BATTERY PL & 585554 & 503211 & $-14 \%$ \\
WHITEHALL STREET & 301734 & 469039 & $55 \%$ \\
PA-PATH WORLD TRADE CNTR & NA & NA & NA \\
SUBTOTAL & 1411167 & $\mathbf{1 5 2 7 5 6 7}$ & $\mathbf{8 \%}$ \\
& & & \\
NON-TOURIST ZONE & & & \\
BROOKLYN BRIDGE & 792302 & 742405 & $-6 \%$ \\
CHAMBERS STREET & 458643 & 446255 & $-3 \%$ \\
PARK PLACE & 1030182 & 1047076 & $2 \%$ \\
CITY HALL & 73397 & 143029 & $95 \%$ \\
FULTON STREET & 813079 & 969553 & $19 \%$ \\
WALL STREET & 1258560 & 1141815 & $-9 \%$ \\
FULTON \& WILLIAM STREETS & 778820 & 686271 & $-12 \%$ \\
SUBTOTAL & $\mathbf{5 2 0 4 9 8 3}$ & $\mathbf{5 1 7 6 4 0 4}$ & $\mathbf{- 1 \%}$
\end{tabular}


Table 4: Average Number of Panhandlers per Walk by Year

$\begin{array}{lll} & \mathbf{2 0 1 4} & \mathbf{2 0 1 5} \\ \text { East Broadway } & 1.44 & 2.13 \\ \text { West Broadway } & 3.55 & 3.32 \\ \text { Crossover } & 0.40 & 1.34 \\ \text { Northwest } & 3.71 & 1.77 \\ \text { Total } & \mathbf{9 . 1 0} & \mathbf{8 . 5 6}\end{array}$

Note: Missing observations were replaced by the mean panhandler count of all other observations of that block in that year 
Table 5: Number of panhandlers as a function of year: Poisson regression

$$
E\left(\ln p_{b s y}\right)=\alpha+\beta Z_{s y}+\phi_{b}+\psi_{y}+\varepsilon_{b s y}
$$

\begin{tabular}{lcc} 
& count & count \\
\hline Rain Dummy & -0.271 & -0.077 \\
Max Temperature & $(0.192)$ & $(0.174)$ \\
& 0.075 & 0.001 \\
Max Temperature Squared & $(0.055)$ & $(0.044)$ \\
& -0.000 & -0.000 \\
Year Dummy = 1 for 2015 & $(0.000)$ & $(0.000)$ \\
& 0.147 & -0.277 \\
Hour Fixed Effects & $(0.252)$ & $(0.190)$ \\
& Yes & No \\
Day of Week Fixed Effects & Yes & Yes \\
Week Fixed Effects & & \\
& Yes & Yes \\
Block Fixed Effects & Yes & Yes \\
Constant & $-7.673^{* *}$ & -2.462 \\
& $(2.112)$ & $(1.724)$ \\
\hline Pseudo R-squared & 0.2596 & 0.2285 \\
Number of Observations & 2,405 & 2,405 \\
LR chi2 & 475.84 & 418.84 \\
Prob $>$ chi2 & 0.000 & 0.000 \\
\hline
\end{tabular}


Table 6: Average Number of Panhandlers by Zone by Year

\begin{tabular}{lll} 
Zone & $\mathbf{2 0 1 4}$ & $\mathbf{2 0 1 5}$ \\
\hline Tourist & 0.65 & 1.12 \\
Broadway & 3.65 & 3.08 \\
Other & 2.41 & 2.74 \\
Total & $\mathbf{6 . 9 5}$ & $\mathbf{6 . 8 1}$
\end{tabular}

Note: Missing observations were replaced by the average for all other block-fronts in that zone for that year. 
Table 7: Number of panhandlers by zone by year: Poisson regression

\begin{tabular}{lc}
\hline & count \\
& $(1)$ \\
\hline Rain Dummy & -0.265 \\
Max Temperature & $(0.171)$ \\
& 0.063 \\
Max Temperature Squared & $(0.051)$ \\
& -0.000 \\
Tourist zone*Dummy2015 & $(0.000)$ \\
& $0.696^{*}$ \\
Broadway zone*Dummy2015 & $(0.309)$ \\
& -0.281 \\
Other zone*Dummy2015 & $(0.349)$ \\
Block Fixed Effects & 0.261 \\
Hour Fixed Effects & $(0.266)$ \\
& Yes \\
Day Fixed Effects & \\
Week Fixed Effects & Yes \\
Constant & Yes \\
\hline Pseudo R-squared & \\
Wumber of Observations & Yes \\
Prob chi2 & \\
\hline
\end{tabular}

$+p<0.10,{ }^{*} p<0.05,{ }^{* *} p<0.01$ 
Table 8a: Number of panhandlers as a function of intuitive score: Poisson regression

\begin{tabular}{lc} 
& count \\
\hline Rain dummy & -0.244 \\
Max Temperature & $(0.188)$ \\
& 0.068 \\
Max Temperature Squared & $(0.052)$ \\
& -0.000 \\
Hour Fixed Effects & $(0.000)$ \\
& Yes \\
Day Fixed Effects & Yes \\
Week Fixed Effects & Yes \\
Block Fixed Effects & No \\
Very Good & $1.074^{* *}$ \\
Good & $(0.172)$ \\
& $0.991^{* *}$ \\
Maybe & $(0.162)$ \\
No & -0.060 \\
Constant & $(0.176)$ \\
& - \\
Pseudo R-squared & \\
No. of Observations & \\
Prob $>$ chi2 & \\
\hline
\end{tabular}

$+p<0.10, * p<0.05, * * p<0.01$ 
Table 8b: Number of panhandlers as a function of structured score: Poisson regression

\begin{tabular}{lc}
\hline & $\begin{array}{c}\text { Coefficient } \\
(\text { Std. } \\
\text { Error) }\end{array}$ \\
\hline Rain dummy & -0.227 \\
& $(0.187)$ \\
Max Temperature & 0.070 \\
& $(0.050)$ \\
Max Temperature Squared & -0.000 \\
& $(0.000)$ \\
Hour Fixed Effects & Yes \\
& \\
Day Fixed Effects & Yes \\
& \\
Week Fixed Effects & Yes \\
Block rating $=6$ & $1.795^{\mathrm{a}}$ \\
Block rating $=5$ & $(0.274)$ \\
& $0.961^{\mathrm{a}}$ \\
Block rating $=4$ & $(0.288)$ \\
& $1.129^{\mathrm{a}}$ \\
Block rating $=3$ & $(0.275)$ \\
Constant & $0.881^{\mathrm{a}}$ \\
& $(0.291)$ \\
Pseudo R-squared & $-8.192^{\mathrm{a}}$ \\
No. of Observations & $(1.913)$ \\
\hline & 0.1107 \\
& 2,365 \\
& 4732.91 \\
& 0.000 \\
\hline
\end{tabular}

$+p<0.10, * p<0.05, * * p<0.01$ 
Table 9a: Number of Blocks by Intuitive Score

\begin{tabular}{lr}
\hline Block Intuition & No. of Blocks \\
\hline Very Good & 8 \\
Good & 13 \\
Maybe & 23 \\
No & 26 \\
\hline
\end{tabular}

Table 9b: Number of Blocks by Structured Score

\begin{tabular}{lr}
\hline Block Rating & No. of Blocks \\
\hline 6 & 12 \\
5 & 11 \\
4 & 21 \\
3 & 16 \\
\hline
\end{tabular}


Table 10a: Poisson Regression of Panhandling Measuring Effects of Nearby Block Fronts Using Structured Score

$$
\text { (1) } \ln p_{b t}=\alpha+\beta X_{t}+\gamma E_{b}+\delta n_{b} d_{b t}+\eta\left(1-n_{b}\right) D_{b t}+\varepsilon_{b t}
$$

(2) $\ln p_{b t}=\alpha+\beta X_{t}+\gamma E_{b}+\delta n_{b} d_{b t}+\eta\left(1-n_{b}\right) D_{b t}+\phi n_{b} r_{b t}+\psi\left(1-n_{b}\right) R_{b t}+\varepsilon_{b t}$

\begin{tabular}{|c|c|c|}
\hline & $\begin{array}{c}\text { count } \\
(1)\end{array}$ & $\begin{array}{c}\text { count } \\
(2)\end{array}$ \\
\hline Rain Dummy & $\begin{array}{l}-0.387^{*} \\
(0.170)\end{array}$ & $\begin{array}{l}-0.391^{*} \\
(0.170)\end{array}$ \\
\hline Max Temperature & $\begin{array}{l}0.094+ \\
(0.049)\end{array}$ & $\begin{array}{r}0.095+ \\
(0.049)\end{array}$ \\
\hline Max Temperature Squared & $\begin{array}{l}-0.001 \\
(0.000)\end{array}$ & $\begin{array}{l}-0.001 \\
(0.000)\end{array}$ \\
\hline Structured score & $\begin{array}{r}0.349 * * \\
(0.049)\end{array}$ & $\begin{array}{l}0.371 * * \\
(0.051)\end{array}$ \\
\hline$n_{b} d_{b t}$ Occupied neighbors (interior) & $\begin{array}{r}-0.285+ \\
(0.151)\end{array}$ & $\begin{array}{l}-0.306^{*} \\
(0.151)\end{array}$ \\
\hline$\left(1-n_{b}\right) D_{b t}$ Occupied neighbor (not interior) & $\begin{array}{c}0.343 \\
(1.797)\end{array}$ & $\begin{array}{l}3.180 \\
(2.627)\end{array}$ \\
\hline$n_{b} r_{b t}$ Attractive neighbors (interior) & - & $\begin{array}{l}-0.144^{*} \\
(0.060)\end{array}$ \\
\hline $\begin{array}{l}\left(1-n_{b}\right) R_{b t} \text { Attractive neighbor (not } \\
\text { interior) }\end{array}$ & - & $\begin{array}{c}-0.197^{*} \\
(0.082)\end{array}$ \\
\hline Week Fixed Effects & Yes & Yes \\
\hline Hour Fixed Effects & Yes & Yes \\
\hline Constant & $\begin{array}{c}-9.077^{* *} \\
(1.785)\end{array}$ & $\begin{array}{c}-8.636^{* *} \\
(1.796)\end{array}$ \\
\hline Pseudo R-squared & 0.1032 & \\
\hline Number of Observations & 2,365 & 2,365 \\
\hline LR chi2 & 185.93 & 193.16 \\
\hline Prob > chi2 & 0.000 & 0.000 \\
\hline
\end{tabular}


Table 10b: Using Intuitive Score

(1) $\ln p_{b t}=\alpha+\beta X_{t}+\gamma E_{b}+\delta n_{b} d_{b t}+\eta\left(1-n_{b}\right) D_{b t}+\varepsilon_{b t}$

(2) $\ln p_{b t}=\alpha+\beta X_{t}+\gamma E_{b}+\delta n_{b} d_{b t}+\eta\left(1-n_{b}\right) D_{b t}+\phi n_{b} r_{b t}+\psi\left(1-n_{b}\right) R_{b t}+\varepsilon_{b t}$

\begin{tabular}{lcc}
\hline & count & count \\
& $(1)$ & $(2)$ \\
\hline Rain Dummy & $-0.355^{*}$ & $-0.358^{*}$ \\
& $(0.169)$ & $(0.169)$ \\
Max Temperature & $0.090+$ & $0.091+$ \\
& $(0.049)$ & $(0.049)$ \\
Max Temperature Squared & -0.001 & -0.001 \\
& $(0.000)$ & $(0.000)$ \\
Intuitive score & $0.441^{* *}$ & $0.440^{* *}$ \\
& $(0.056)$ & $(0.056)$ \\
$n_{b} d_{b t}$ Occupied neighbors (interior) & -0.245 & $-0.260+$ \\
& $(0.156)$ & $(0.157)$ \\
$\left(1-n_{b}\right) D_{b t}$ Occupied neighbor (not interior) & 2.468 & $4.875+$ \\
& $(1.815)$ & $(2.645)$ \\
$n_{b} r_{b t}$ Attractive neighbors (interior) & - & -0.021 \\
& & $(0.077)$ \\
$\left(1-n_{b}\right) R_{b t}$ Attractive neighbor (not interior) & - & -0.132 \\
Week Fixed Effects & & $(0.110)$ \\
Hour Fixed Effects & Yes & Yes \\
Constant & & \\
& Yes & Yes \\
Pseudo R-squared & & $-8.295^{* *}$ \\
LR chi2 of Observations & $-8.321^{* *}$ & $(1.773)$ \\
Prob $>$ chi2 & $(1.770)$ & 0.1088 \\
& 0.1078 & 2,365 \\
& 2,365 & 196.07 \\
& 194.27 & 0.000 \\
\hline
\end{tabular}

$+p<0.10, * p<0.05, * * p<0.01$ 
Appendix A-1

Number of panhandlers by year: Logistic regression

\begin{tabular}{lcc}
\hline & count & count \\
\hline Rain Dummy & -0.254 & 0.016 \\
& $(0.240)$ & $(0.218)$ \\
Max Temperature & $0.123+$ & 0.023 \\
& $(0.067)$ & $(0.055)$ \\
Max Temperature Squared & -0.001 & -0.000 \\
& $(0.001)$ & $(0.000)$ \\
Year Dummy = 1 for 2015 & 0.102 & $-0.405+$ \\
& $(0.295)$ & $(0.225)$ \\
Hour Fixed Effects & Yes & No \\
& & \\
Day of Week Fixed Effects & Yes & Yes \\
Week Fixed Effects & Yes & Yes \\
Block Fixed Effects & Yes & Yes \\
Constant & & \\
& -9.113 & -2.471 \\
\hline Pseudo R-squared & $(2.488)$ & $(1.989)$ \\
Number of Observations & 0.2485 & 0.2092 \\
LR chi2 (100) & 1,984 & 1,984 \\
Prob > chi2 & 380.11 & 319.93 \\
\hline & 0.000 & 0.000 \\
\hline
\end{tabular}

$+p<0.10,{ }^{*} p<0.05,{ }^{*} * p<0.01$ 


\section{Appendix A-2}

Number of panhandlers by zone by year: Logistic regression

\begin{tabular}{lc}
\hline & count \\
& $(1)$ \\
\hline Rain Dummy & -0.228 \\
& $(0.240)$ \\
Max Temperature & 0.108 \\
& $(0.070)$ \\
Max Temperature Squared & -0.001 \\
& $(0.001)$ \\
Tourist zone*Dummy2015 & 0.657 \\
& $(0.423)$ \\
Broadway zone*Dummy2015 & -0.356 \\
& $(0.423)$ \\
Other zone*Dummy2015 & 0.253 \\
Block Fixed Effects & $(0.337)$ \\
& Yes \\
Hour Fixed Effects & \\
Day Fixed Effects & Yes \\
Week Fixed Effects & Yes \\
Constant & \\
Pseudo R-squared & Yes \\
Wald chi2(102) & \\
\hline
\end{tabular}

$+p<0.10, * p<0.05, * * p<0.01$ 